Research Article

\title{
Damage Detection in Plates with the Use of Laser-Measured Mode Shapes
}

\author{
Ziemowit Dworakowski (D), Kajetan Dziedziech (D), Pawel Zdziebko (D), \\ and Krzysztof Mendrok ii \\ Department of Robotics and Mechatronics, AGH University of Science and Technology, Kraków, Poland \\ Correspondence should be addressed to Ziemowit Dworakowski; zdw@agh.edu.pl
}

Received 18 May 2020; Accepted 24 September 2020; Published 23 October 2020

Academic Editor: Fabio Rizzo

Copyright (C) 2020 Ziemowit Dworakowski et al. This is an open access article distributed under the Creative Commons Attribution License, which permits unrestricted use, distribution, and reproduction in any medium, provided the original work is properly cited.

\begin{abstract}
This paper presents the use of laser vibrometer measurements to detect and locate damage in a metal plate. An algorithm based on local spatial filters was selected, and for the purpose of comparison, the fault location was also determined based on the wavelet analysis of mode shapes. The research was carried out first on the created finite element model of aluminum plate, where two kinds of damage of increasing size and temperature change were simulated. After obtaining positive results, a laboratory experiment was carried out, which consisted of measuring the vibration of the aluminum plate with the laser vibrometer in undamaged condition, at increased temperatures, and with various damage scenarios. The conclusions of the laboratory experiment confirm the damage detection capabilities of the methods but question their damage localization potential.
\end{abstract}

\section{Introduction}

Among low-frequency fault detection methods, a group based on the analysis of changes of modal model parameters can be distinguished. The simplest ones are based on the analysis of changes in natural frequency $[1,2]$. Unfortunately, the natural frequencies are not sensitive enough to small damage, and the detection is additionally disturbed by changes in external conditions, for example, temperature. It is also difficult to locate damage only from frequency changes, although such studies have been carried out [3]. The modal damping coefficient is much more sensitive to damage [4-6], but its estimation from measurement data is usually the least accurate. Mode shapes are probably the most commonly used in damage detection [7-11] due to the possibility of localization and less sensitivity to changes in external conditions.

Research on damage detection and location is usually based on the study of elements with simple geometry such as a beam or plate. This is a reasonable approach because these classes of objects can be later extended to real technical objects such as girders, pillars, or masts in the case of beams or panels of hull plating, walls, or ceilings for plates. Many methods are developed in such a way that first their effectiveness is checked for the beams and then for the plates and later possibly more complex geometries. As an example, one can consider a comparison of an object's mode shapes (measured or estimated for the current state) with their polynomial approximation (for undamaged state) examined first for beams [12] and later for plates [13]. Another method of applying mode shapes to detect damage is to analyze modal strain energy, which was also first developed for beam elements [14], and then expanded to plate elements [15]. The surface interpolation method was also proved first on the basis of numerical simulation and then in the experiment $[16,17]$. Another example is the detection and location of the damage by means of wavelet analysis of the shape of the natural vibrations, which was first developed for the beams $[18,19]$ and next for the plates [19-21] or frames [22].

The authors of this paper used a similar approach in their research. They first tested their method for damage detection and localization on beam structures $[23,24]$. The method consisted of filtering the frequency characteristics of the object in the current state with a modal filter (MF) tuned to the data collected in the reference state. The characteristics and local modal filters (LMFs) are defined separately for 
every region of the tested structure. The method showed great potential for practical application because it had such advantages as the simplicity of the algorithm, low demand for computing power, work on measurement data without the need to identify the modal model at every diagnosis, and a certain resistance to changes in external conditions. In addition, its results were easy to interpret.

In this paper, the authors verify the operation of the method for a plate-like structure. Numerical and experimental studies were carried out using a measurement made with a laser vibrometer. More than 20 scenarios were considered, including two locations of damage of different sizes and changes in ambient temperature. In addition, the obtained results were compared with the wavelet-based method in a similar setup as proposed by other researchers $[19,20]$.

The paper is organized as follows: Section 2 provides a theoretical description of all the methods used in the paper. Section 3 provides numerical verification of methods suitability for damage detection and localization. Section 4 provides a similar verification for a complementary laboratory experiment. Finally, Section 5 summarizes and concludes the paper.

\section{Description of Localization Algorithms}

This chapter describes the methods used to locate the damage in the plate: the tested method of local modal filters and the reference method of wavelet shape mode analysis.

2.1. Local Modal Filters Method. The modal filter is a tool to extract the modal coordinates of each mode from the system outputs by mapping the response vector from the physical space to the modal space [25]. It was first introduced by Baruh and Meirovitch in 1982 [26] to solve the control problem of distributed parameter systems. The method for application of modal filter for damage detection was presented in other articles $[27,28]$. In brief, the MFs tuned to selected natural frequencies are constructed and used to filter the obtained frequency response functions (FRFs). A set of damage indices corresponding to the set of MFs is obtained by subtracting the ideal (baseline) response and currently obtained one. Finally, a damage index (DI) is calculated for the obtained difference. In this work, a simple Root Mean Square (RMS) of signal difference is used as a DI. The value is calculated from equation (1), where $\mathrm{DI}_{\mathrm{MF}}$ refers to the DI calculated globally using MF tuned to particular frequency; $H_{B}(f)$ and $H_{M}(f)$ refer to values of FRF obtained for response filtered using this filter at a given frequency for baseline and measurement, respectively. Finally, $F$ refers to the frequency range in which the calculations are performed:

$$
\mathrm{DI}_{\mathrm{MF}}=\sqrt{\left(\sum_{f=0}^{F}\left|H_{B}(f)-H_{M}(f)\right|\right)^{2}} \mathrm{DI}_{\mathrm{MF}} .
$$

The idea to extend the method by adding damage localization $[23,29]$ is based on the fact mentioned above that damage disturbs the mode shapes only locally. It is then possible to divide an object into areas and build a number of local modal filters (LMFs) for data coming only from these regions. In areas without damage, the shape of modes does not change, and the modal filter keeps working; there are no additional peaks on the filter output. When a group of sensors placed near the damage is considered, mode shape is disturbed locally due to damage, and the LMF does not perfectly filter the characteristics measured by these sensors. The graphical presentation of this idea is shown in Figure 1. Details on the minimum number of sensors in subsequent groups, their mutual configuration, and the influence of these parameters on the localization accuracy are described in [23].

To make localization more straightforward, a DI is also used here. $\mathrm{DI}_{\mathrm{LMF}}$ is build using the same equation as $\mathrm{DI}_{\mathrm{MF}}$, but data for FRF calculation come only from a selected neighborhood of the point in which the integrity of the structure is evaluated. More information on the damage index form and ways of its application and visualization can also be found in [23].

2.1.1. Extension of the LMF to Plate Structures. The extension of the method to 2D structures (e.g., plates) is performed by a calculation of LMFs in local groups using a $2 \mathrm{D}$ neighborhood of selected width and height. From here, the method is performed precisely as its $1 \mathrm{D}$ counterpart. The width and height of the neighborhood are metaparameters of the method; in this analysis, a $3 \times 3$ neighborhood ( 9 measurement points) was used.

2.1.2. Spatial Group Measurement. There is a possibility of using a spatial group measurement damage index $\left(\mathrm{DI}_{\mathrm{SGM}}\right)$ to distinguish damage from environmental effects. The method is derived from guided-wave-based damage detection $[30,31]$ and later adopted to local modal filtration for beams [32]. Its principle is shown in Figure 2: the method requires a calculation of DI for many different points on a structure and then compounds them using equation (2). Although the concept is very simple, it is powerful enough to make the method relatively insensitive to temperature-induced changes of single DIs. In this work, $\left(\mathrm{DI}_{\mathrm{SGM}}\right)$ is calculated for the whole plate, based on all the local DIs obtained from LMFs:

$$
\mathrm{DI}_{\mathrm{SGM}}=\max \left(\mathrm{DI}_{\mathrm{LMF}}\right)-\operatorname{median}\left(\mathrm{DI}_{\mathrm{LMF}}\right) \text {. }
$$

2.2. Wavelet Analysis Method. The mode shapes, in general, are used for damage localization because cracks or other local faults disturb the mode shapes only locally. Unfortunately, for the small-sized damage, the effect is hardly visible (the change of mode shape is minimal). In many applications to show the small changes between the two quantities, their difference is presented. That was the main idea behind the proposed method. Instead of analyzing the mode shapes itself, it is better to take into account their difference. One can find in the literature the example of mode shapes 


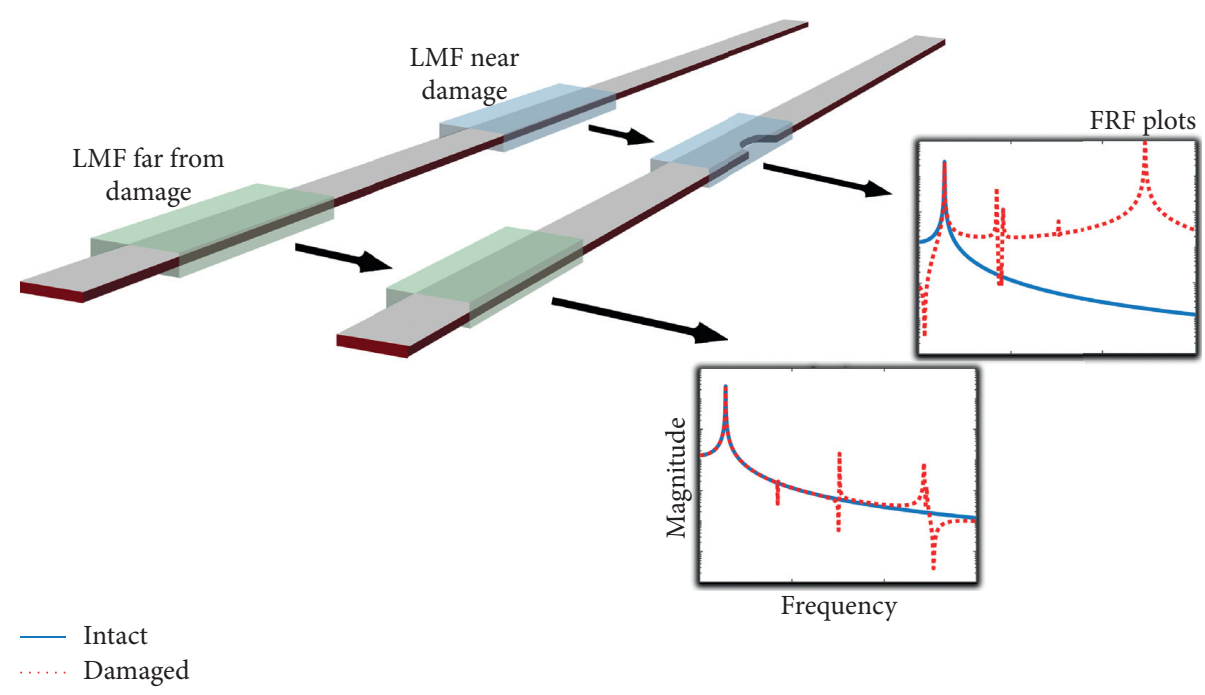

FIGURE 1: Scheme of localization procedure based on modal filtration.

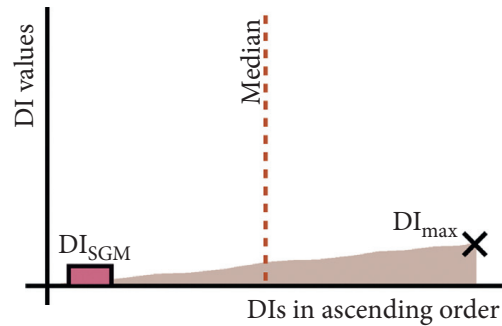

(a)

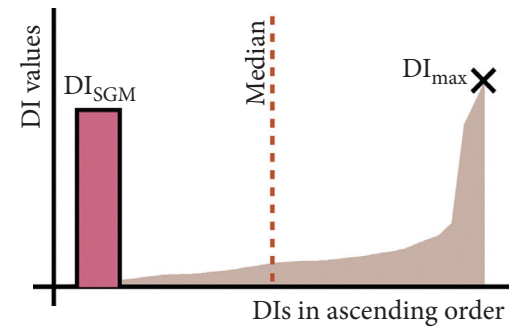

(b)

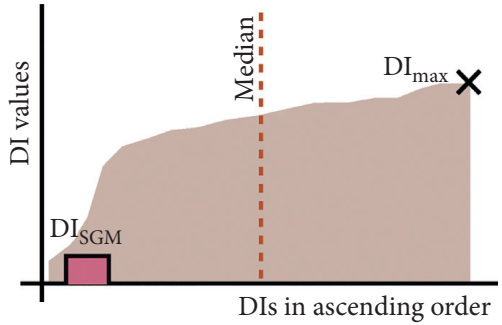

(c)

FIGURE 2: SGM damage index principle: (a) intact state, (b) presence of damage, and (c) environmental change.

derivatives subtraction in order to detect and localize damage better [33]. The idea of the method was proposed by Ziaja and Mendrok [34] and can be summarized in two steps. First, the mode shapes of the structure in the current stage are subtracted from the reference counterpart. Next, the wavelet analysis is used similarly as in the work [19]. The scheme of diagnostic procedure based on the proposed approach is presented in Figure 3.

The proposed approach has the following advantages: it is sensitive for relatively small damage and provides the possibility for better results interpretation. In opposite to that, the method is no longer baseline free, and the computational cost is a little bit bigger. The procedure presented in Figure 3 is designed for beam-like structures. In order to apply it to the plates, the authors divided the measuring point net into lines and analyzed each line separately in a horizontal and vertical direction. Afterward, the results are presented jointly. In order to simplify the later references to the algorithm described, it was designated for the purpose of this paper as the wavelet (WV) method.

2.2.1. Extension of the Wavelet-Based Method to $2 D$ Structures. The extension of the method was performed by a calculation of wavelet coefficients in rows and columns of the measurement grid. Then, for each point, a mean value for all the scales is stored. Finally, both maps (acquired from rows and columns of the grid) are averaged. The analytic Morlet wavelet is used for calculations. $\mathrm{DI}_{\mathrm{WV}}$ is calculated as a maximum of this averaged map.

\section{Numerical Verification}

In both the numerical and laboratory experiments, a similar aluminum plate fixed on one end has been used. In both experiments, the plate was subjected to measurements in different temperature setups and for different damage states. Both the simulation and the real experiment were designed to reflect each other in terms of temperatures used, damage size and location, point of excitation, points of data acquisition of data for modal analysis, and so on. The plate dimensions, along with damage locations, are presented in Figure 4(a). Points of data acquisition (nodes for which position was recorded in numerical simulation and locations of laser vibrometer measurement described in Section 4) are presented in Figure 4(b).

3.1. Experimental Setup. The Finite Element Method (FEM) was used for the Real Eigenvalue Analysis of the aluminum plate. As a result of simulations, the natural frequencies and 


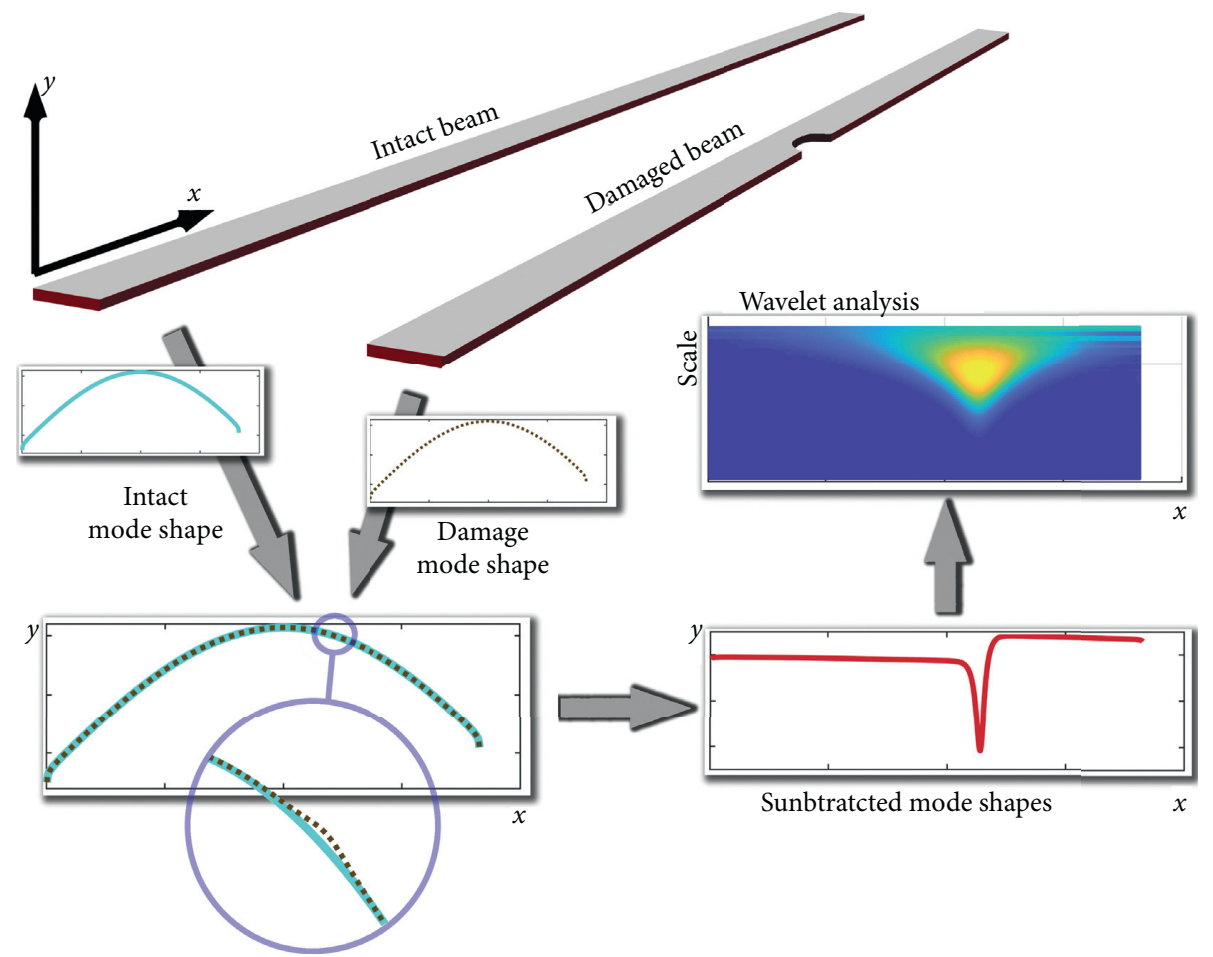

FIGURE 3: Scheme of localization procedure based on modal filtration.

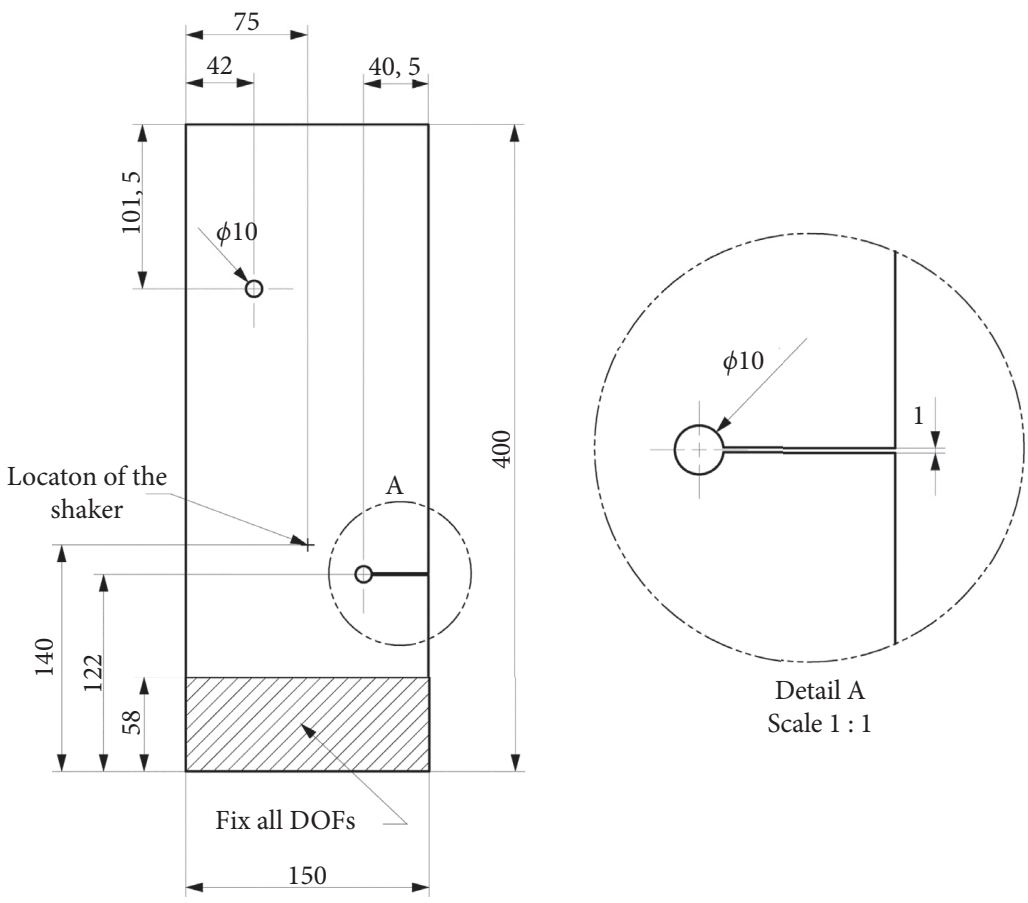

(a)

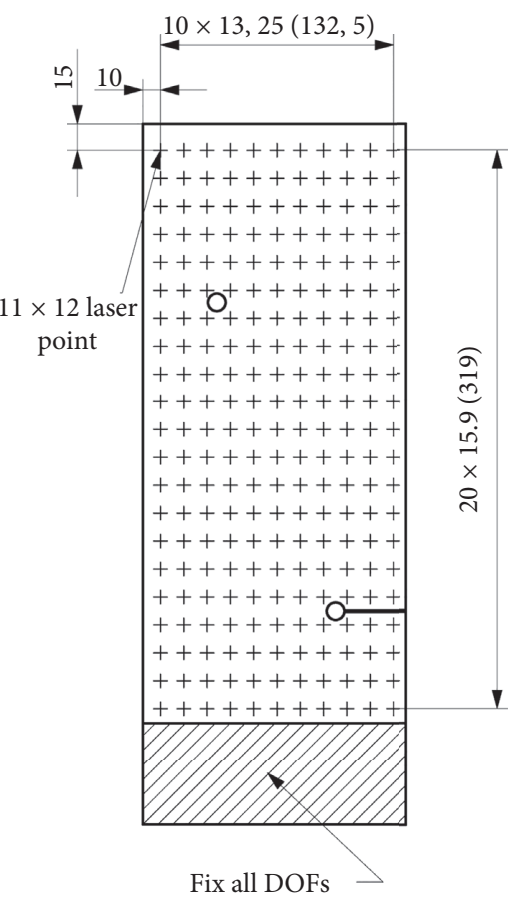

(b)

Figure 4: (a) Plate dimensions and damage locations. (b) Points for which data were recorded.

mode shapes were for the intact and damaged aluminum plate. The analyses were carried out employing the Altair HyperWorks software and the MSC Nastran solver. The Lanczos method was used to determine natural frequencies and mode shapes of the plate. The computations were performed separately for the following cases:

(1) Full plate, fixation on one end. 
(2) Hole in the top part of the plate, 10 different diameters, fixation on one end.

(3) Hole in the bottom part of the plate, 10 different diameters, fixation on one end.

A detailed list of plate states simulated numerically along with the first five natural frequencies obtained in simulation is provided in Table 1. Since the cut marked as Damage 3 was introduced at the last stage of the practical experiment and the numerical simulation already served its purpose, the final damage case was not copied in simulation.

The FEM model view is shown in Figure 5. It was formulated using 2D shell elements (quads and trias). The thickness of the elements was $2 \mathrm{~mm}$. White points indicate FEM nodes that correspond to the laser-measured points in the laboratory experiment. Next, displacements of these nodes were exported, and based on them, the normal model was reproduced in the analysis. In order to accurately reflect experimental conditions, the adopted constraints were applied so it would reflect the dimensions of the clamp jaws planned in the laboratory experiment. In Figure 5(a), the spider-shaped RBE2 element applied in the FEM model provides fixation of the selected area in all six DOFs. The finer mesh was generated in the area of holes; see Figure 5(b). The element was modeled as rigidly fixed to the aluminum plate to take into account the influence of the presence of the inductor attachment; see Figure 5(c).

3.2. Results. In Figure 6, the diagnosis obtained with LMFs tuned to the first three natural frequencies is presented for cases S\#7, S\#11, and S\#15. Cases to show were chosen without any particular intent as the indications were consistent: for particular damage, the shape of obtained maps for all its stages was mostly similar, with amplitude being the only significant difference.

In Figure 7, the diagnosis obtained with the WV approach for the first three modes of vibration is presented for similar cases (S\#7, S\#11, and S\#15).

The LMF method with its SGM component aimed at temperature compensation works as intended. For temperature-induced changes, the majority of the LMFs report similar differences, while for damaged cases, the diagnosis is localized in close proximity to damage. It is worth noting that, for Damage 1 (here case S\#11), the position of the damage on the horizontal axis was detected accurately while on the vertical axis, the method missed by $1 / 3$ of a specimen's width.

The WV method in case of temperature-induced changes caused localized indications in the bottom part of a plate. However, the overall level of indication is at least an order of magnitude lower than those recorded for damaged cases.

Aggregated results of the diagnostic procedure for both methods and both approaches (with and without SGM index) are provided in Figure 8 and Table 2. All the indications are normalized with respect to the highest value obtained, so they could be compared on one plot for all three modes. For the exact numerical values obtained by all the methods, the reader is referred to Table 2. For LMF and MF
TABLE 1: List of numerical simulations along with the first five natural frequencies of the plate.

\begin{tabular}{|c|c|c|c|c|c|c|}
\hline Simulation & Specimen state & $\mathrm{F} 1$ & $\mathrm{~F} 2$ & F3 & $\mathrm{F} 4$ & F5 \\
\hline S\#1-S\#2 & Intact, $T=20 \mathrm{C}$ & 14.93 & 70.97 & 92.76 & 228.32 & 259.24 \\
\hline S\#3 & Intact, $T=25 \mathrm{C}$ & 14.91 & 70.84 & 92.60 & 227.92 & 258.78 \\
\hline S\#4 & Intact, $T=30 \mathrm{C}$ & 14.88 & 70.72 & 92.43 & 227.51 & 258.32 \\
\hline S\#5 & Intact, $T=35 \mathrm{C}$ & 14.85 & 70.59 & 92.27 & 227.10 & 257.85 \\
\hline S\#6 & Intact, $T=40 \mathrm{C}$ & 14.83 & 70.47 & 92.10 & 226.70 & 257.39 \\
\hline S\#7 & Intact, $T=45 \mathrm{C}$ & 14.80 & 70.34 & 91.94 & 226.29 & 256.92 \\
\hline S\#8 & $\begin{array}{c}\text { Damage } 1 \\
3 \mathrm{~mm}\end{array}$ & 14.93 & 70.97 & 92.75 & 228.28 & 259.19 \\
\hline S\#9 & $\begin{array}{l}\text { Damage 1, } \\
5 \mathrm{~mm}\end{array}$ & 14.94 & 70.97 & 92.73 & 228.22 & 259.11 \\
\hline S\#10 & $\begin{array}{l}\text { Damage 1, } \\
7.5 \mathrm{~mm}\end{array}$ & 14.94 & 70.97 & 92.71 & 228.13 & 258.98 \\
\hline S\#11 & $\begin{array}{l}\text { Damage } 1 \text {, } \\
10 \mathrm{~mm}\end{array}$ & 14.95 & 70.98 & 92.65 & 227.96 & 258.73 \\
\hline S\#12 & $\begin{array}{l}\text { Damage } 2, \\
3 \mathrm{~mm}\end{array}$ & 14.93 & 70.96 & 92.77 & 228.31 & 259.25 \\
\hline S\#13 & $\begin{array}{l}\text { Damage } 2, \\
5 \mathrm{~mm}\end{array}$ & 14.92 & 70.94 & 92.77 & 228.28 & 259.26 \\
\hline S\#14 & $\begin{array}{l}\text { Damage } 2, \\
7.5 \mathrm{~mm}\end{array}$ & 14.91 & 70.92 & 92.77 & 228.25 & 259.27 \\
\hline S\#15 & $\begin{array}{l}\text { Damage } 2, \\
10 \mathrm{~mm}\end{array}$ & 14.88 & 70.87 & 92.77 & 228.18 & 259.30 \\
\hline
\end{tabular}

methods, the indication rises with damage increase and with temperature increase as well. It is worth noting that the LMF method appears to be much less sensitive to temperature differences than a simple MF method due to its SGM component lowering the overall diagnosis if most of the indications are high. That allowed for the detection of both kinds of damage, at least for filters tuned to the third mode.

In contrast to that, the WV method appears to be entirely insensitive to temperature-induced changes while preserving good detection capability.

In terms of localization capabilities, both methods score results in a similar range, with WV method having a slightly better outcome: on average, WV detected damage 1.16 measurement points away from its actual location (calculated using the Manhattan metric between the actual damage location and the maximum indication of the method) while the LMF resulted in 1.75 error value. It is worth noting that localization efficiency is not uniform and varies for damage cases and modes under investigation. The second damage was far easier to localize with both methods scoring almost perfect matches ( 0 and 0.16 error values for the $\mathrm{WV}$ and LMF methods, respectively). First damage, on the other hand, resulted in 2.33 and 3.33 error values for the WV and LMF methods, respectively. It is worth noting that interesting results could have been obtained for higher modes. For instance, the best modewise performance was scored by the LMF method tuned to the fifth natural frequency. In this example, the localization was almost perfect for both damage cases ( 0.12 localization error). The best results for the $\mathrm{WV}$ method were obtained for modes 1 and 3 ( 0.5 averaged error value in both cases).

In summary, during the simulation-based experiment, it was confirmed that both methods have comparable damage 


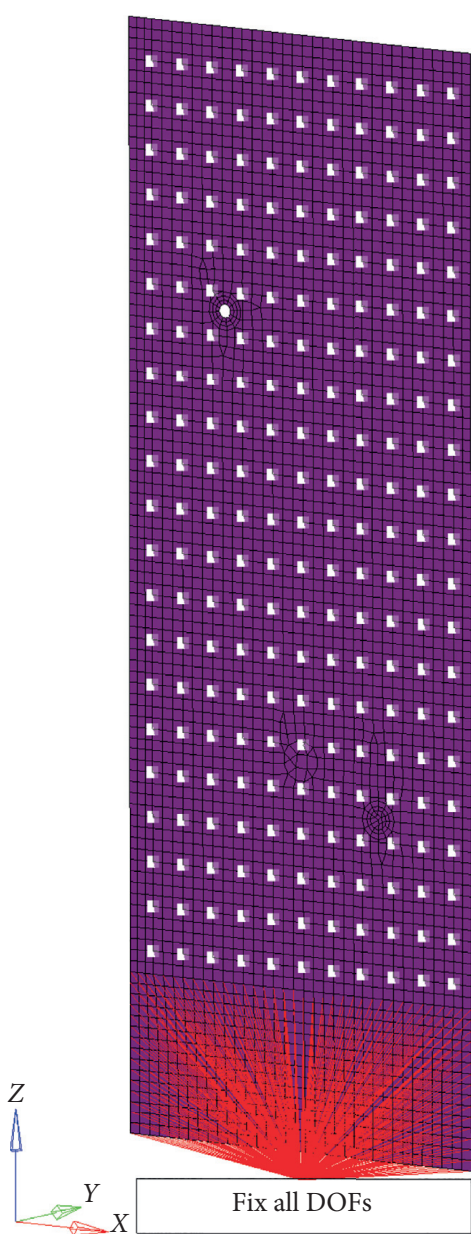

(a)

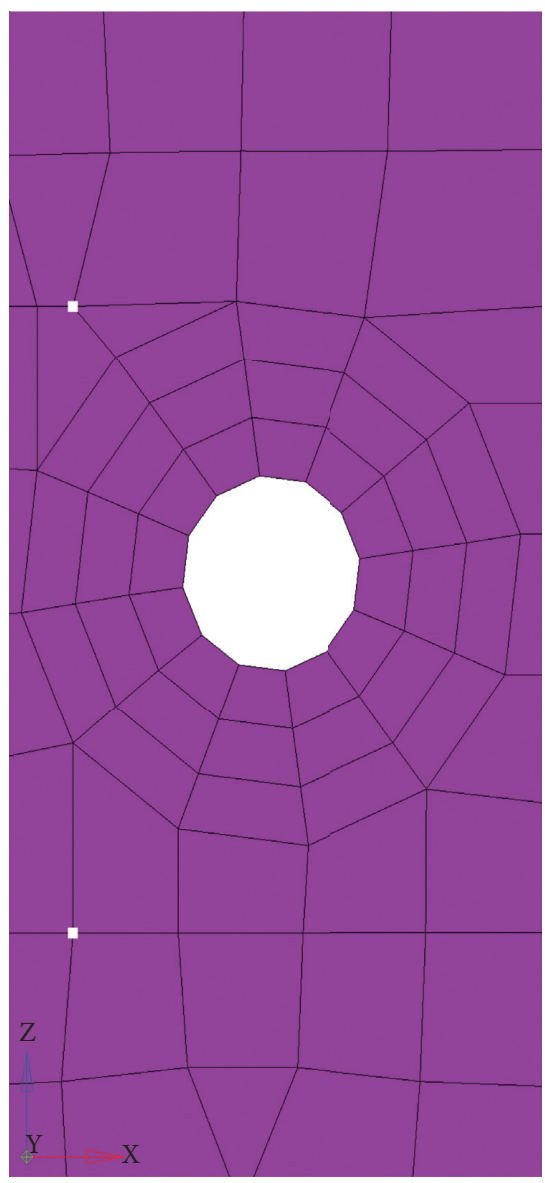

(b)

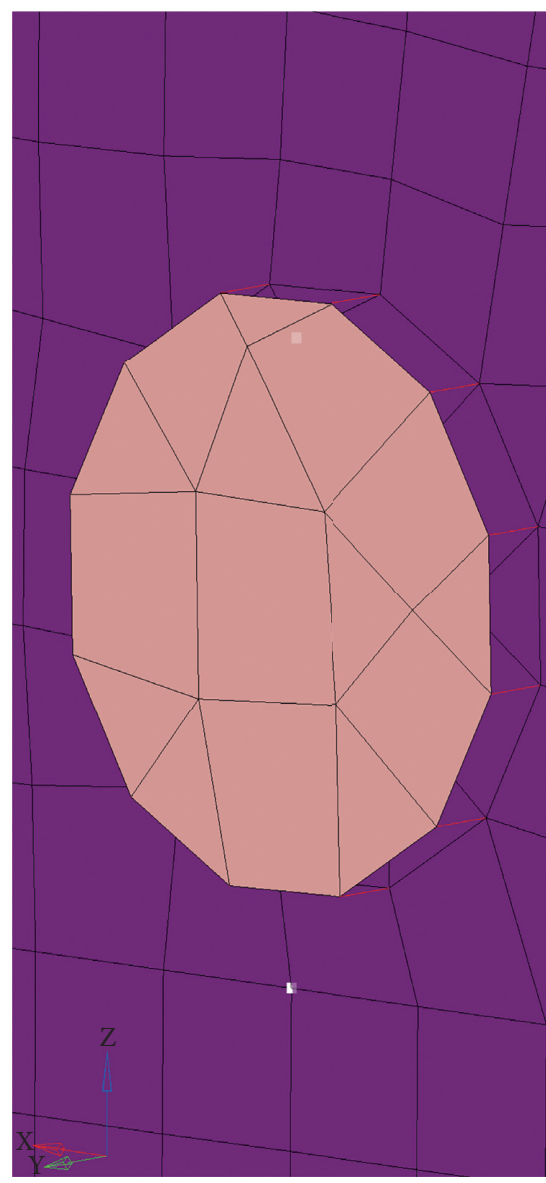

(c)

Figure 5: (a) FEM model. (b) Detail of mesh around the damage. (c) Detail of mesh in excitation point.

localization capabilities with WV method being significantly better in terms of both damage detection and localization.

\section{Practical Verification}

4.1. Experimental Setup. A FEM model described in Section 3 was copied in a laboratory test bench with one difference regarding damage introduction. In a numerical simulation, both faults were introduced separately to undamaged specimens. In the practical verification, both faults were introduced one after another to one specimen (see Figures 4(a) and 9). After initial verification of obtained data, it was found that results were far from expected; thus, the second damage was extended by adding a horizontal cut from damage to the side of the specimen.

The test object was clamped in a pneumatic vice in a cantilever manner as presented in Figure 9(a). Polytec PSV400-3D Scanning Laser Vibrometer was used as a data acquisition system and excitation signal generation. The electrodynamic shaker, The Modal Shop Smart Shaker K2007E01, was used to excite the structure. Shaker was attached to the structure via PCB 288D01 impedance head measuring force and acceleration at a driving point. The measurement grid used was $21 \times 11$ points equally spaced on the surface of the test specimen to cover the entire structure and capture mode shapes properly (see Figure 4(b)). White noise excitation was used with a bandwidth of $1 \mathrm{kHz}$. The sampling frequency was set to $2.56 \mathrm{kHz}$, and the total acquisition time was $60 \mathrm{~s}$. Frequency response functions were calculated using the $\mathrm{H} 1$ estimator, with a window length of $4 \mathrm{~s}$ and an overlap of $50 \%$; this translated to 29 averages. The high quality of the measurement was assured by the very high values of coherence function at the resonant frequencies. Finally, the mode shapes were estimated via poly-reference least squares complex exponential estimator.

In order to check whether the method is sensitive to actual damage or reacts only to a slight modification of a test stand induced during, for example, damage introduction, reassembly of a test stand was performed between selected measurements. Reassembly included reattachment of the plate to the vice in such a manner that the location of measurement points was not changed significantly (i.e., locations of laser vibrometer measurement points were marked, so after reassembly, the same points were measured). 

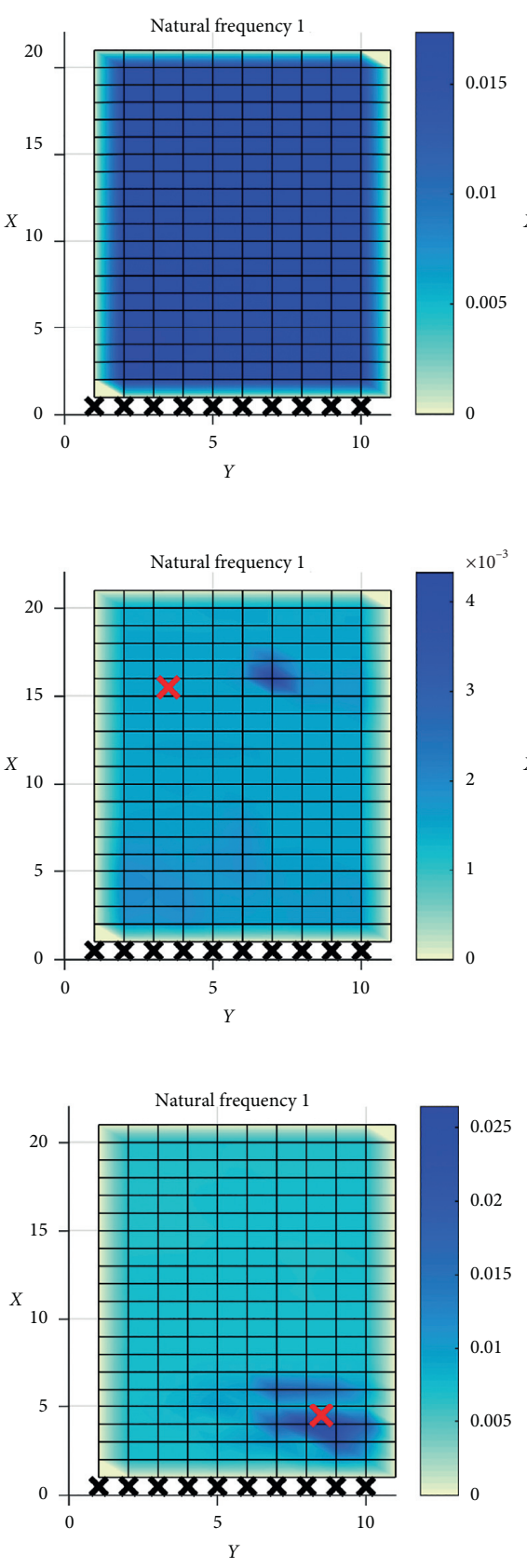

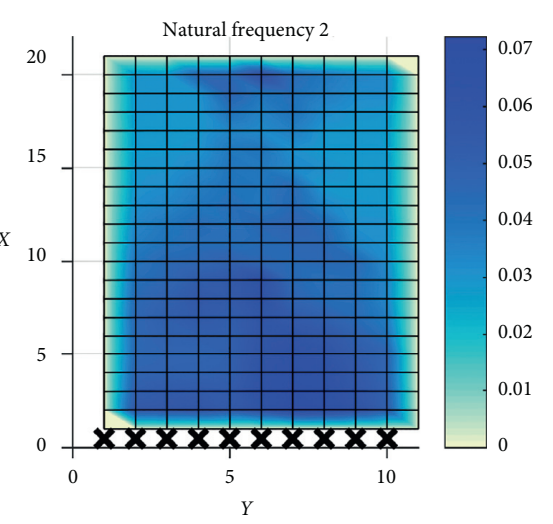

(a)

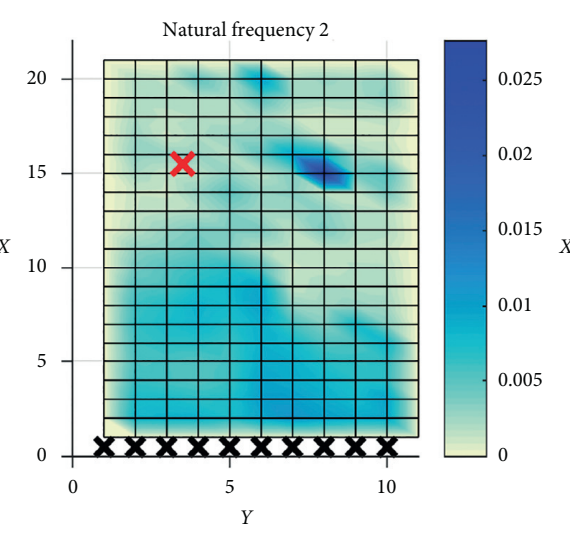

(b)
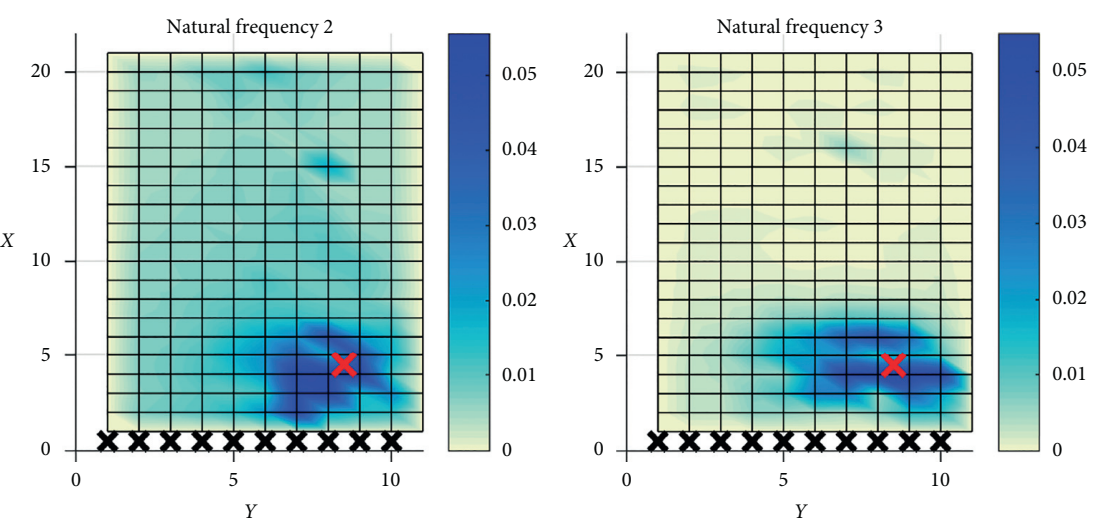

(c)

Figure 6: LMF-based damage detection for (a) S\#7, (b) S\#11, and (c) S\#15 case. Black X marks refer to fix. Red X marks refer to damage locations.

The description of structure states during the experiment, along with the first five natural frequencies registered for each measurement, is presented in Table 3. Note that, for two final stages of damage (M\#23-M\#26), two completely new modes appeared. The diagnostic procedure covered this issue: new modes were omitted in the wavelet-based evaluation of structural state.

4.2. Initial Analysis of Mode Shapes. The laser-measured mode shapes for an intact state $(\mathrm{S} \# 2)$ are depicted in Figure 10. It is worth noting that the experimentally measured mode shapes are smooth and clear and do not contain any outliers. This observation is true for all of the acquired measurements proving the high quality of obtained data. The introduction of extensive damage, however, caused several modes to mix and new modes to appear. For instance, in cases $\mathrm{M} \# 23-\mathrm{M} \# 26$, two new modes with frequencies around $65 \mathrm{~Hz}$ and $200 \mathrm{~Hz}$ appeared. For that reason, a Modal Assurance Criterion (MAC) was used to match modes with each other. Three first matching modes matching in shape and frequency were selected for further processing. 


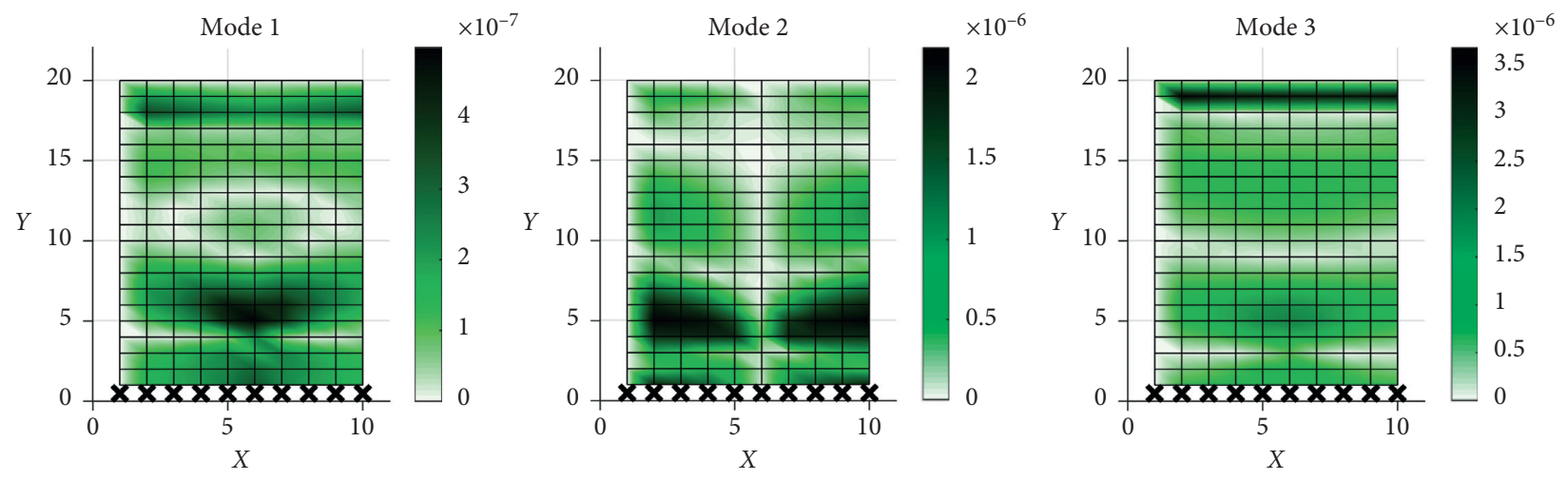

(a)
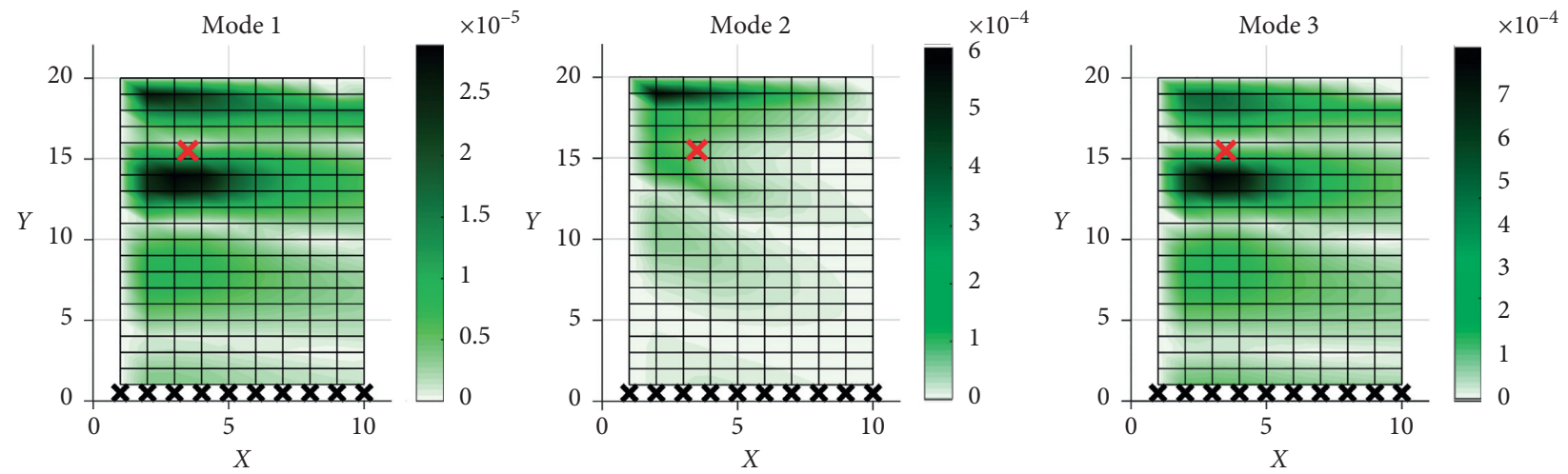

(b)
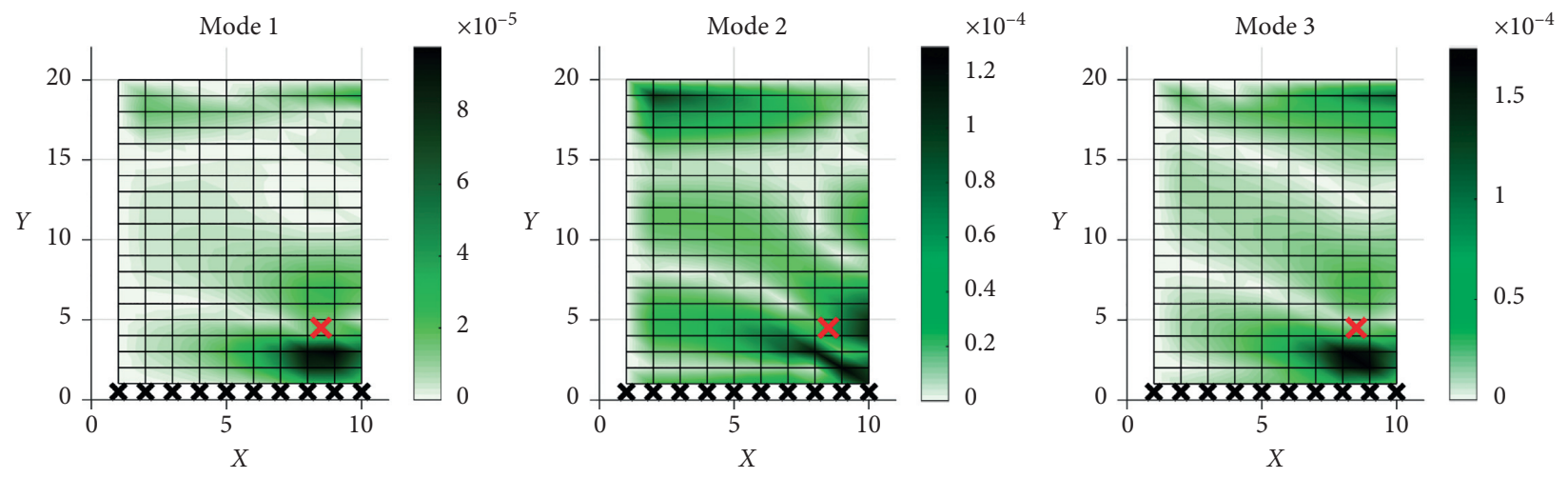

(c)

Figure 7: Wavelet-based damage detection for (a) S\#7, (b) S\#11, and (c) S\#15 case. Black X marks refer to fix. Red X marks refer to damage locations.

4.3. Damage Detection. For all the registered states of the specimen, a full procedure including MF, LMF, and mode shapes subtraction followed by the wavelet-based damage detection was performed. In each case, acquired DIs were compounded using a maximum indication and using the SGM approach to filter out temperature-induced changes. The parameters for both methods were optimized to provide the best performance available. Unfortunately, the obtained results were far from expected. After the initial analysis, it was found that no definitive damage indication was found

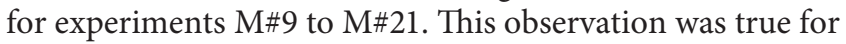
various setups of the wavelets used, many different scale setups in the case of the wavelet-based method, and various neighborhood shapes in the case of the LMF. For that reason, another round of experiments was carried out. Its goal was to increase Damage 2 to such size so that it would be clearly detected by at least one of the methods. The aggregated results for damage detection are provided in Figure 11 and Table 4 . The first damage ( $M \# 9$ to $M \# 12)$ was arguably not detected by any of the methods. The closest to detection was MF and LMF approach tuned to third natural frequency (3rd mode, marked as triangles in the figure). Second damage (M\#13 to M\#21) was again not detected by any of the methods except maybe by the WV approach, but only for the 


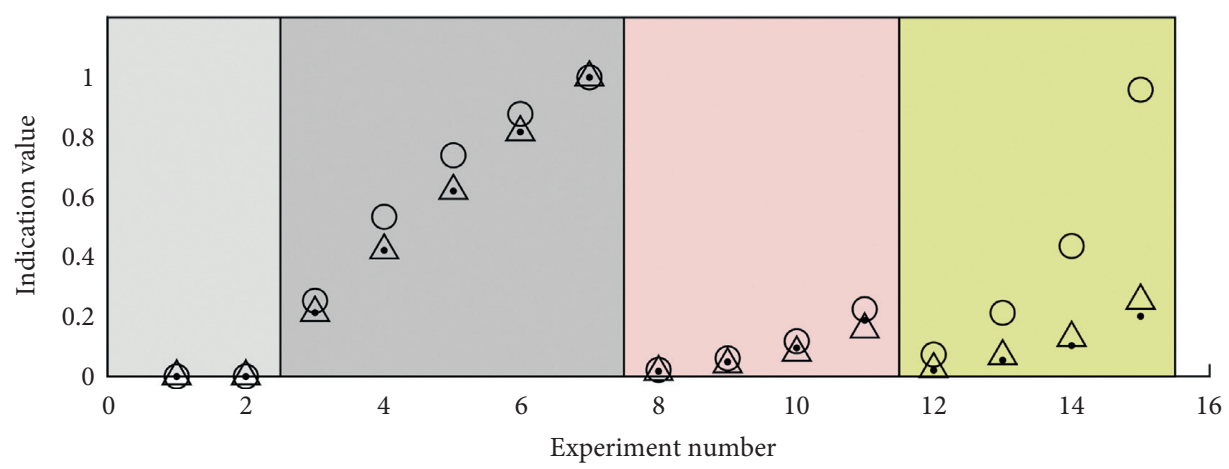

Mode 1

- Mode 2

$\triangle$ Mode 3

(a)

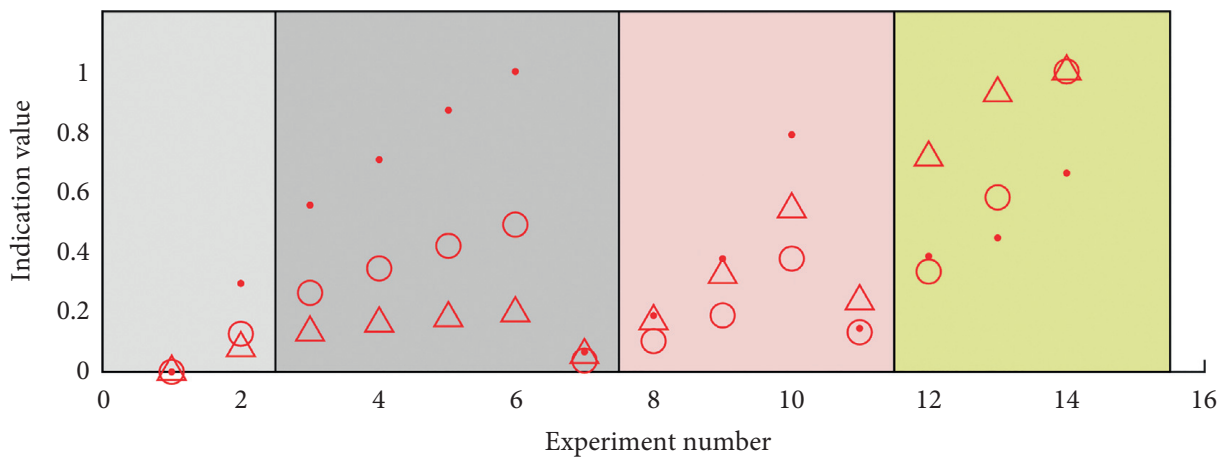

Mode 1

- Mode 2

$\triangle$ Mode 3

(b)

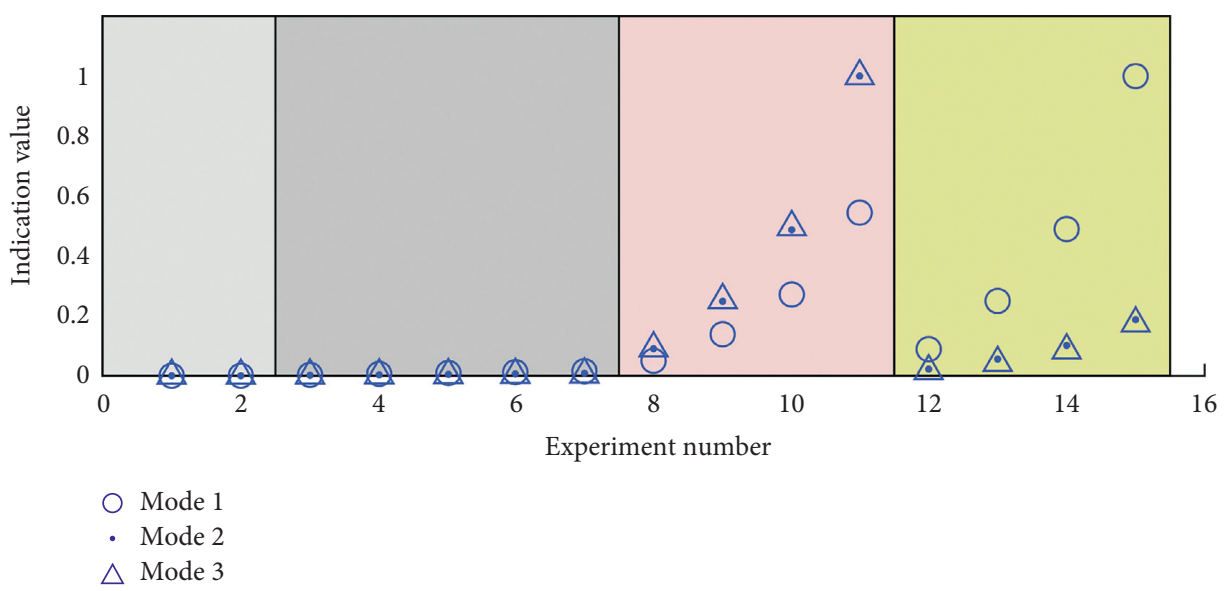

(c)

FIGURE 8: Results of damage detection for the first three modes: (a) MF method, (b) LMF method, and (c) WV method. Coloring of areas refers to damage scenarios under investigation, with temperature rise marked in grey and damage cases 1 and 2 marked with light and dark light red and yellow, respectively. Values are normalized so each time maximum indication of the given method would equal 1.

first mode and only for the first three stages of damage. Later, an increase in the damage did not increase this DI. Finally, the third damage (M\#22 to $\mathrm{M} \# 27$ ) resulted in a significant increase of the MF and LMF indications for the three modes under investigation, clearly exceeding the maximum value obtained for intact states. The difference between intact state indication and the value of DI at the end of the experiment is the highest for mode 2 . The WV method did not result in any visible increase except maybe for three final damage states for modes 2 and 3. 
TABLE 2: Damage detection results of the numerical experiment.

\begin{tabular}{|c|c|c|c|c|c|c|c|c|c|c|c|c|c|c|c|c|}
\hline \multirow{2}{*}{ Number } & \multirow{2}{*}{ pecimen state } & \multicolumn{5}{|c|}{$\mathrm{DI}_{\mathrm{MF}}$} & \multicolumn{5}{|c|}{$\mathrm{DI}_{\mathrm{SGM}}$} & \multicolumn{5}{|c|}{$\mathrm{DI}_{\mathrm{WV}}$} \\
\hline & & M1 & M2 & M3 & 44 & 45 & M1 & $\mathrm{M} 2$ & M3 & M4 & M5 & M1 & M2 & M3 & M4 & M5 \\
\hline & & & & & & & & & & & & & & & & \\
\hline & & & & & & & & & & & & & & & & \\
\hline & & & 22 & 421 & 20 & 74 & 63 & & 131 & & & & & .002 & & .001 \\
\hline & & 739 & 620 & 621 & 619 & 73 & 44 & 07 & 0.161 & 91 & & 09 & & 0.002 & 07 & .001 \\
\hline & & & 7 & 17 & 19 & & & & 79 & & & 12 & 06 & 0.003 & & 0.001 \\
\hline & & & & 00 & & & & & & & & & & 04 & & .002 \\
\hline & & 22 & 18 & 015 & 17 & 24 & 37 & 66 & 56 & 55 & 64 & 50 & 90 & .091 & 104 & 0.091 \\
\hline & & & 049 & .041 & .046 & 64 & 02 & .187 & 0.169 & & & & 0.248 & 0.253 & 0.273 & 0.254 \\
\hline & & & 0.095 & 0.080 & & & & 0.377 & 0.322 & 0.344 & & & & 0.496 & 0.523 & 0.498 \\
\hline & & & 38 & 57 & & & & 90 & & & & & & 1.000 & & 1.000 \\
\hline & & 73 & 021 & 025 & 27 & & & 45 & 235 & 27 & & 89 & 0.022 & 0.015 & 0.072 & 0.034 \\
\hline & e $2,5 \mathrm{~mm}$ & 0.213 & .055 & 0.068 & .073 & 0.153 & .334 & 0.385 & 0.713 & 0.713 & 0.453 & 0.250 & 0.055 & 0.043 & 0.182 & 0.096 \\
\hline & & 436 & 103 & 0.129 & 142 & 294 & & 0.446 & 0.927 & 0.736 & & 0.489 & 0.101 & 0.084 & 0.340 & 0.189 \\
\hline S\#15 & Damage $2,10 \mathrm{~mm}$ & 0.959 & 0.201 & 0.254 & 0.287 & 0.588 & 1.000 & 0.662 & 1.000 & 0.932 & 0.703 & 1.000 & 0.187 & 0.174 & 0.682 & 0.388 \\
\hline
\end{tabular}

TABLE 3: Organization of measurements during practical experiment along with the first five natural frequencies of the plate.

\begin{tabular}{|c|c|c|c|c|c|c|}
\hline Measurement no & Specimen state & F1 & $\mathrm{F} 2$ & F3 & $\mathrm{F} 4$ & F5 \\
\hline $\mathrm{M} \# 1-\mathrm{M} \# 4$ & Intact, $T=20 \mathrm{C}$, reassembly & 16.59 & 90.38 & 236.08 & 420.14 & 475.25 \\
\hline $\mathrm{M} \# 5$ & Intact, $T=34 \mathrm{C}$ & 16.62 & 90.24 & 235.53 & 418.07 & 474.29 \\
\hline $\mathrm{M} \# 6$ & Intact, $T=36 \mathrm{C}$ & 16.56 & 90.16 & 235.26 & 421.77 & 473.89 \\
\hline $\mathrm{M} \# 7$ & Intact, $T=30 \mathrm{C}$ & 16.59 & 90.50 & 236.45 & 419.16 & 475.50 \\
\hline $\mathrm{M} \# 8$ & Intact, $T=20 \mathrm{C}$, reassembly & 16.64 & 90.59 & 236.68 & 419.65 & 475.74 \\
\hline $\mathrm{M} \# 9$ & Damage $1,5 \mathrm{~mm}$ & 16.65 & 90.58 & 236.63 & 417.83 & 475.50 \\
\hline $\mathrm{M} \# 10$ & Damage $1,7.5 \mathrm{~mm}$ & 16.65 & 90.49 & 236.39 & 418.49 & 475.07 \\
\hline $\mathrm{M} \# 11-\mathrm{M} \# 12$ & Damage $1,10 \mathrm{~mm}$, reassembly & 16.67 & 90.49 & 236.23 & 418.80 & 474.77 \\
\hline $\mathrm{M} \# 14$ & Damage $2,5 \mathrm{~mm}$ & 16.66 & 90.50 & 236.32 & 417.47 & 474.23 \\
\hline M\#15 & Damage $2,7.5 \mathrm{~mm}$ & 16.63 & 90.46 & 236.41 & 411.91 & 474.04 \\
\hline $\mathrm{M} \# 16-\mathrm{M} \# 20$ & Damage $2,10 \mathrm{~mm}$, reassembly & 16.63 & 90.49 & 236.44 & 413.59 & 474.08 \\
\hline $\mathrm{M} \# 21$ & Damage $3,10 \mathrm{~mm}$ (1/4 cut) & 16.82 & 89.40 & 231.47 & 385.26 & 450.84 \\
\hline $\mathrm{M} \# 22$ & Damage $3,20 \mathrm{~mm}(1 / 2$ cut $)$ & 16.69 & 89.15 & 229.78 & 384.73 & 447.43 \\
\hline $\mathrm{M} \# 23$ & Damage $3,30 \mathrm{~mm}$ (3/4 cut) & 16.24 & 65.26 & 87.69 & 200.32 & 226.14 \\
\hline $\mathrm{M} \# 24-\mathrm{M} \# 26$ & Damage $3,40 \mathrm{~mm}$ (full cut), reassembly & 16.25 & 65.26 & 87.75 & 200.24 & 226.34 \\
\hline
\end{tabular}

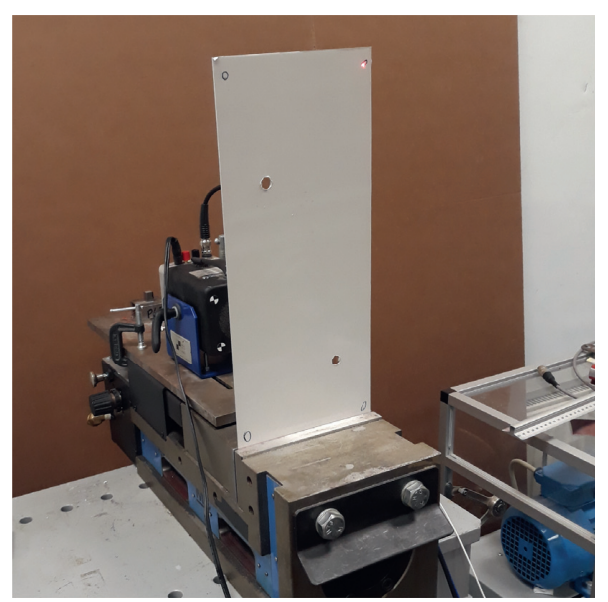

(a)

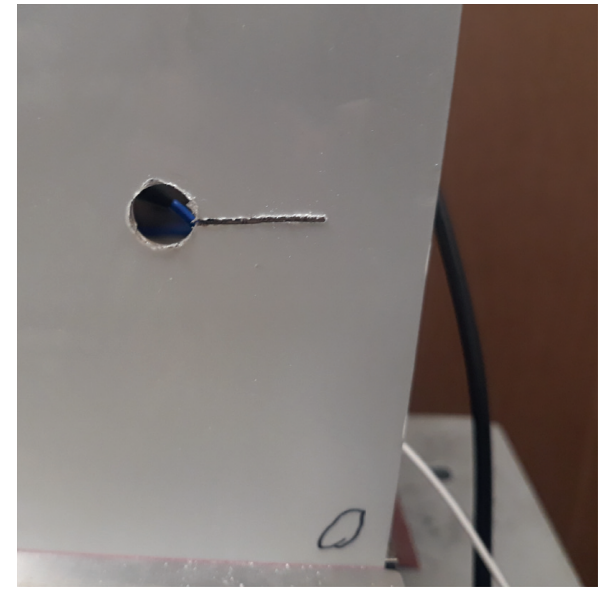

(b)

FIGURE 9: Damage introduced to the specimen in laboratory experiment: (a) specimen clamped in front of the vibrometer with two kinds of damage present and (b) close-up of the first damage with third damage halfway complete. 
TABLE 4: Damage detection results of the laboratory experiment.

\begin{tabular}{|c|c|c|c|c|c|c|c|c|c|c|c|c|c|c|c|c|}
\hline \multirow{2}{*}{ Number } & \multirow{2}{*}{ Specimen state } & \multicolumn{5}{|c|}{$\mathrm{DI}_{\mathrm{MF}}$} & \multicolumn{5}{|c|}{$\mathrm{DI}_{\mathrm{SGM}}$} & \multicolumn{5}{|c|}{$\mathrm{DI}_{\mathrm{WV}}$} \\
\hline & & M1 & M2 & M3 & M4 & 45 & M1 & M2 & M3 & M4 & M5 & M1 & M2 & M3 & M4 & M5 \\
\hline \#1 & & 0 & 00 & 000 & 0 & 0 & 0 & 000 & 000 & 00 & 00 & 00 & 000 & .000 & .000 & 0.000 \\
\hline [\#2 & $\begin{array}{l}\text { Intact, } \\
\text { reass }\end{array}$ & 440 & 084 & 241 & 453 & 461 & 811 & 210 & 200 & 78 & 316 & 203 & 084 & 027 & 27 & .058 \\
\hline $\mathrm{M} \# 3$ & $\begin{array}{l}\text { Intact, } \\
\text { reass }\end{array}$ & 529 & 0.069 & 0.196 & 439 & 447 & 617 & 176 & 0.190 & 277 & 250 & 0.169 & 0.021 & .031 & .252 & 0.068 \\
\hline$x+4$ & & 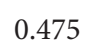 & 064 & 155 & 19 & 0 & 9 & 384 & 0.204 & 65 & 13 & .169 & .021 & .031 & 52 & 0.068 \\
\hline & & & 122 & .216 & & 464 & & 0.303 & 0.148 & & & & .032 & .061 & 72 & 0.462 \\
\hline & & & 0.171 & .529 & & & & & 0.202 & & & & & .030 & & \\
\hline & & & & 370 & & & & & 0.477 & & & & & .043 & & .098 \\
\hline & & & 157 & 399 & & 30 & 6 & 20 & 0.598 & & & & 78 & .037 & 65 & 0.080 \\
\hline & & & 155 & 550 & & 71 & & & 0.800 & & & & & 0.074 & & 0.242 \\
\hline & & & 0 & 464 & & & & & 0.488 & & & & & 0.047 & & 0.091 \\
\hline & & & & & & & & & & & & & & & & \\
\hline & & & & 383 & & & & & 0.595 & & & & & 56 & & 0.070 \\
\hline & & & 42 & 659 & & & & 78 & 0.732 & & & & & 0.064 & & 0.400 \\
\hline & & & & 505 & & & & & 0.644 & & & & & & & 0.082 \\
\hline & & & & & & & & & & & & & & & & \\
\hline & & & 54 & 558 & & & & & 0.497 & & & & & 35 & & 0.098 \\
\hline & & & 70 & .498 & 8 & 4 & & 76 & 0547 & & & & & 0.035 & 06 & 0.098 \\
\hline & $\mathrm{im}$ & 695 & 151 & 559 & 38 & 6 & 1 & 295 & 0.465 & 98 & & 84 & 0.039 & .035 & .106 & 09 \\
\hline A\#1S & m, & 0 & 175 & 373 & 16 & 4 & c & 45 & 0.548 & 40 & 59 & 0. & 0.039 & .035 & 106 & .09 \\
\hline 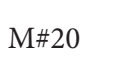 & n, & 600 & 122 & 333 & 488 & 92 & 689 & 0.278 & 0.542 & 0.386 & 20 & 84 & 0.039 & .035 & .106 & 009 \\
\hline $\mathrm{M} \# 21$ & ${ }_{4}^{\text {Damage }}$ & 11 & 0.421 & 0.506 & 44 & 39 & 61 & 18 & 0.358 & 1.000 & 1.000 & 53 & 30 & .160 & 351 & 0.446 \\
\hline $\mathrm{M} \# 22$ & Damage & 636 & .550 & 587 & 569 & 58 & 5 & 392 & 0.149 & 0.306 & 38 & .367 & 0.063 & 0.070 & 357 & .521 \\
\hline $\mathrm{M} \# 2$ & $\begin{array}{r}\text { Damage } \\
4\end{array}$ & 316 & 0.780 & 0.695 & 0.774 & .778 & 1.000 & 0.876 & 0.166 & 0.440 & 0.503 & 0.532 & 0.070 & 0.098 & 0.607 & 0.565 \\
\hline $\mathrm{M} \# 24$ & Dam & 500 & 0.714 & 0.731 & .738 & 5 & 9 & 0.071 & 0.192 & 0.618 & 0.696 & 0.508 & 0.045 & 0.098 & .620 & 1.00 \\
\hline $\mathrm{M} \# 2$ & I & 930 & 0.653 & 1.000 & 1.000 & 1.000 & 0.943 & 0.935 & 0.811 & 0.399 & 0.452 & 0.589 & 1.000 & 1.000 & 0.817 & 0.953 \\
\hline $\mathrm{M} \# 26$ & $\begin{array}{l}\text { Damage } 3 \text {, } \\
\text { (full cut), re }\end{array}$ & 000 & .000 & 923 & 770 & 781 & 927 & 000 & 1.000 & 0.541 & 0.600 & .326 & .270 & 0.295 & .000 & .3 \\
\hline
\end{tabular}

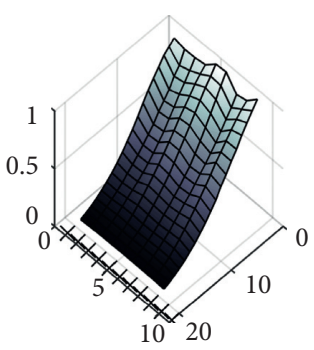

(a)

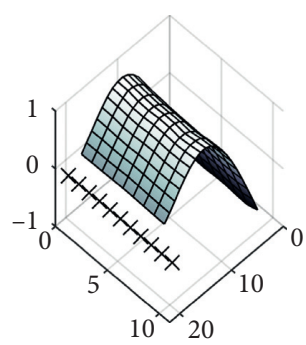

(b)

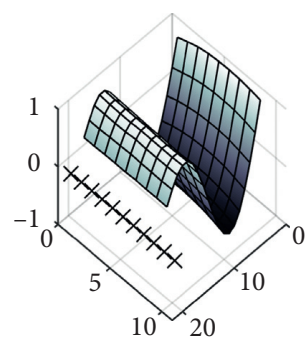

(c)

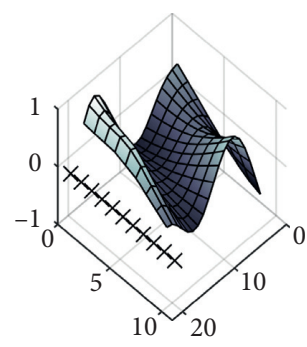

(d)

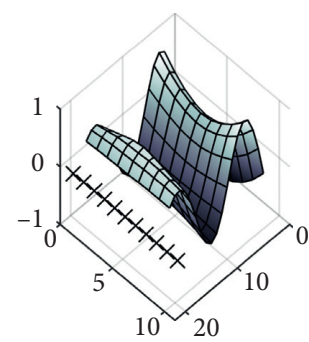

(e)

Figure 10: The first five experimental mode shapes acquired structural state M\#2: (a) mode 1, (b) mode 2, (c) mode 3, (d) mode 4, and (e) mode 5 .

The reasons for such a situation (the apparent lack of success of all the methods unless the damage was nearly catastrophic) will be discussed further in the following sections.
4.4. Mode Shapes Comparison for Intact and Slightly Damaged Cases. The majority of problems with small damage detection are caused by the fact that, despite the high quality of the acquired mode shapes, their subtraction reveals a lot of 


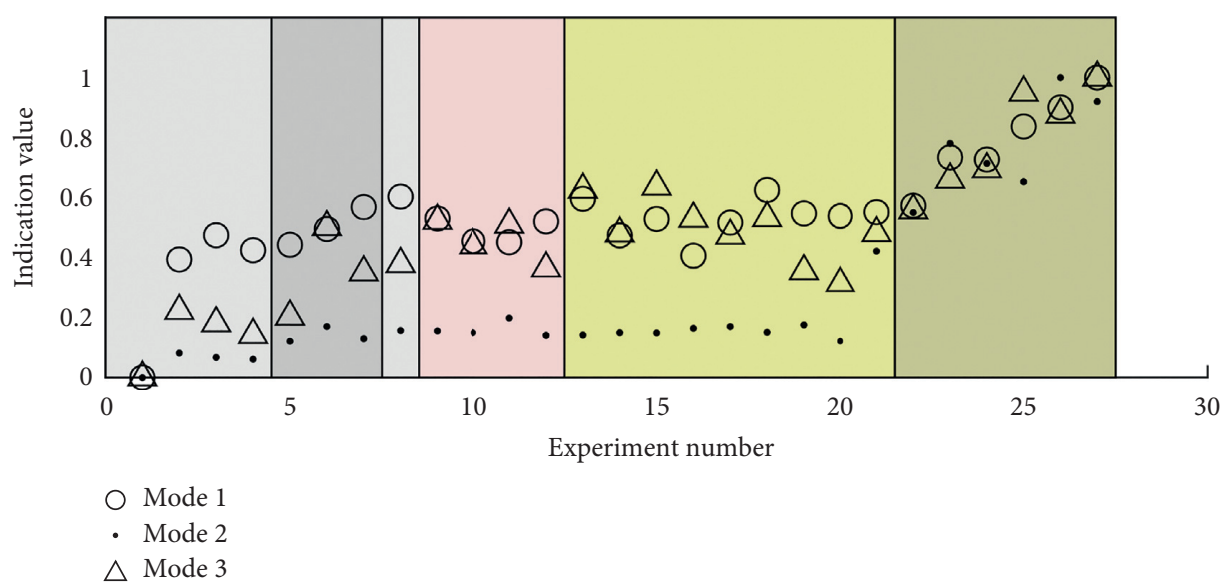

(a)

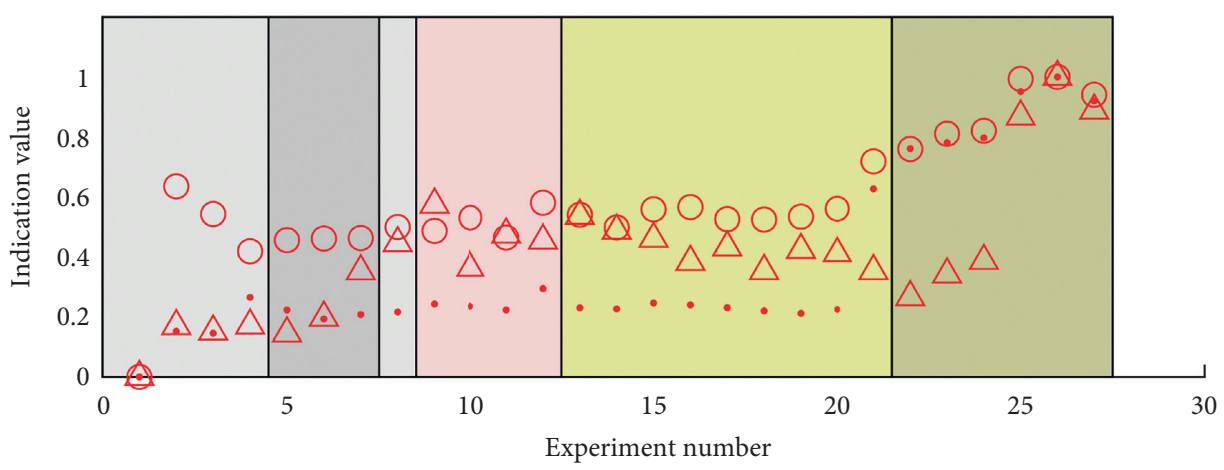

Mode 1

- Mode 2

$\triangle$ Mode 3

(b)

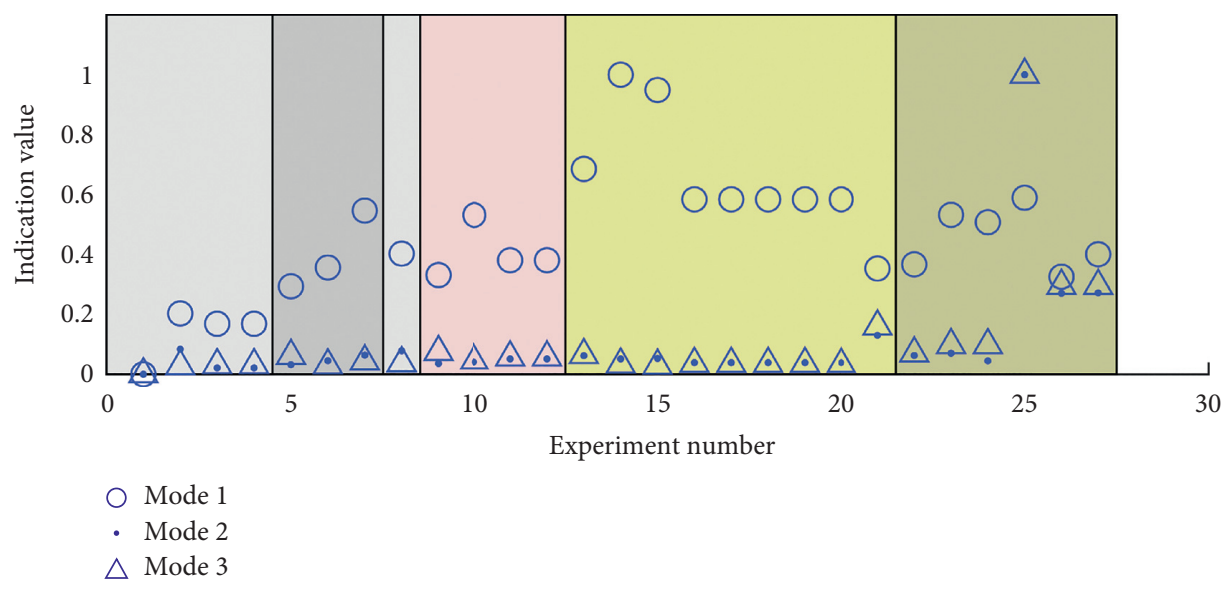

(c)

FIGURE 11: Results of damage detection for the first three modes, for a laboratory experiment, (a) MF method, (b) LMF method, and (c) WV method. Coloring of areas refers to damage scenarios under investigation, with temperature rise marked in dark grey and damage cases 1,2 , and 3 marked with light red, light yellow, and dark yellow, respectively. Values are normalized so each time maximum indication of the given method would equal 1.

hidden noise. The example of the above can be seen in Figure 12. Since mode shapes' differences are not smooth even for an undamaged case, the WV method is hard to use in practice. The smoothness of the MS difference before and after damage introduction is similar. Although the overall difference (e.g., measured as RMS of the difference curve) is slightly higher for the damaged case, there is no clear "break" on the surface indicating local nonlinearity or discontinuity. It is worth noting that the differences for similar states are of similar value even if no reassembly was performed in- 


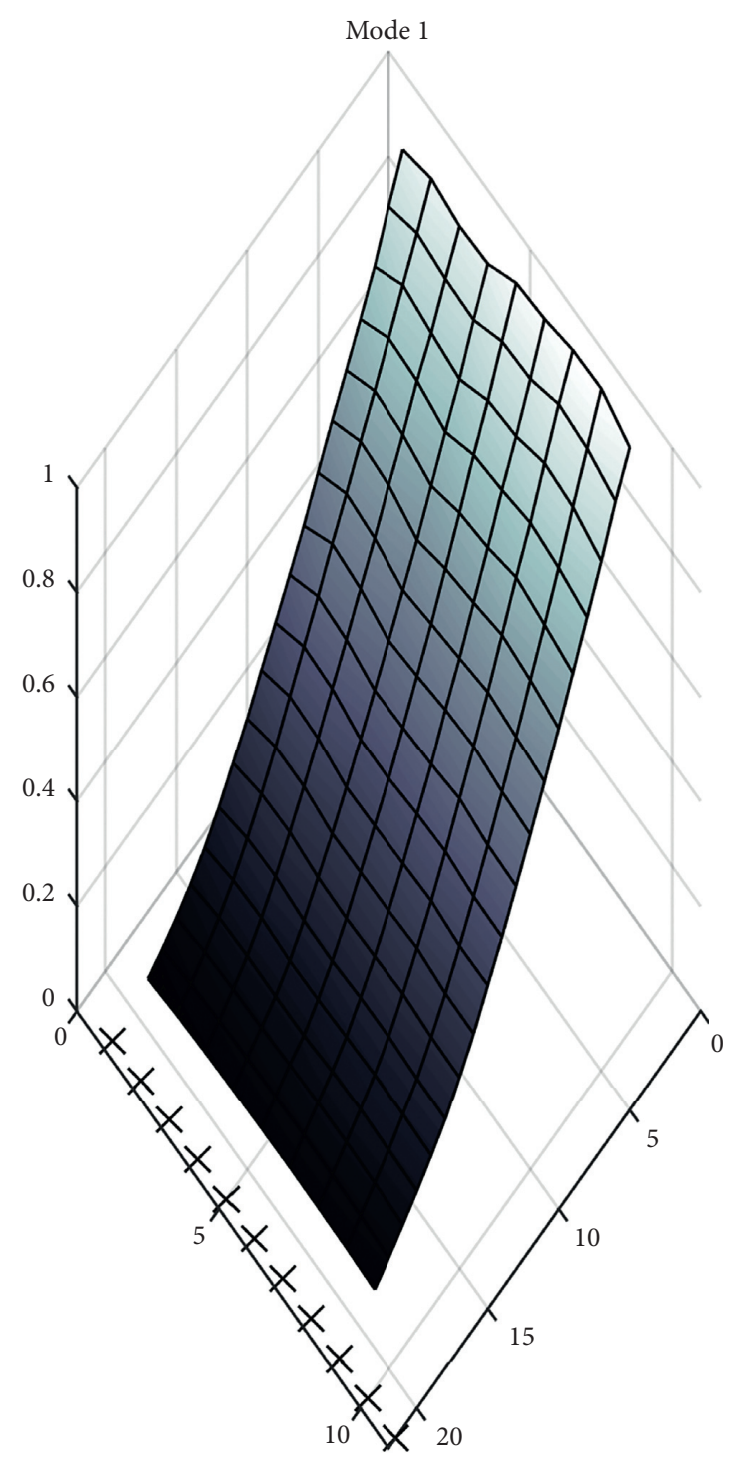

(a)

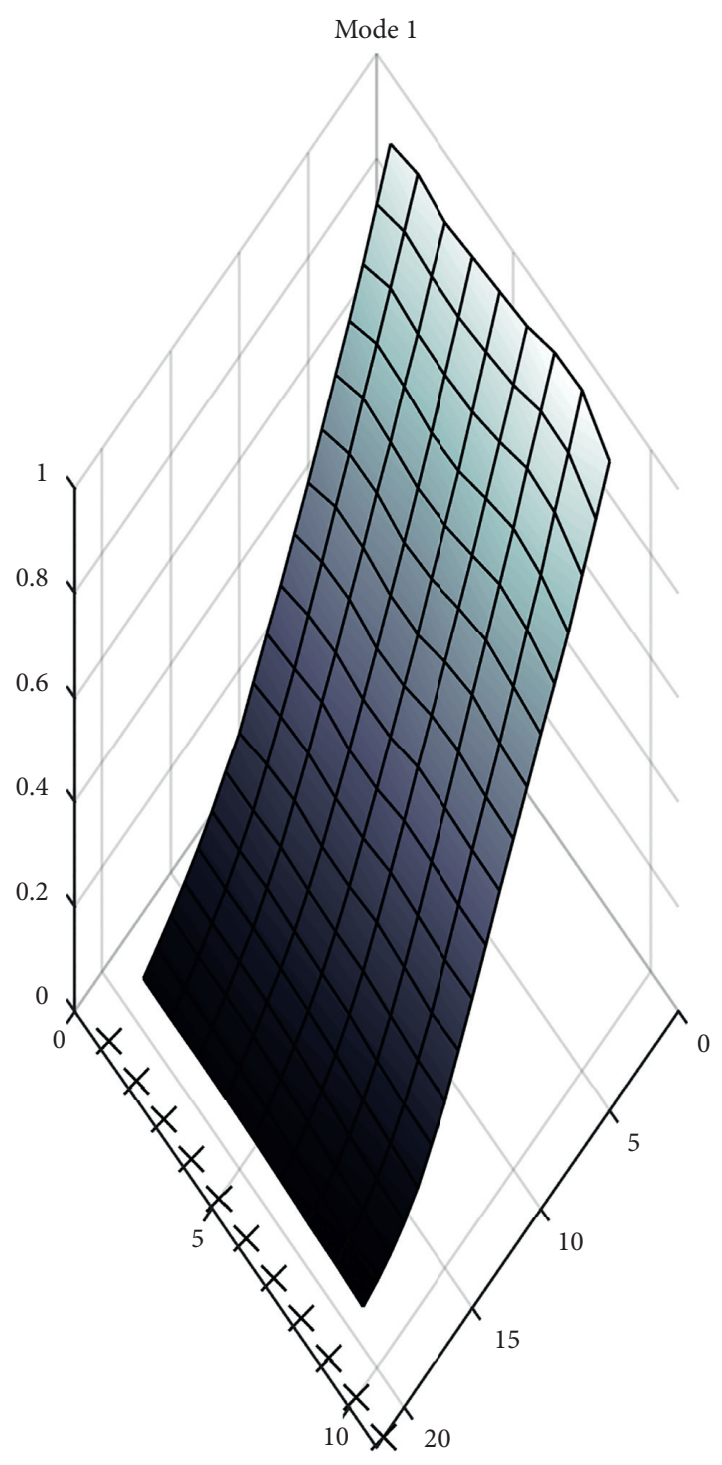

(b)

FIgUre 12: Continued. 


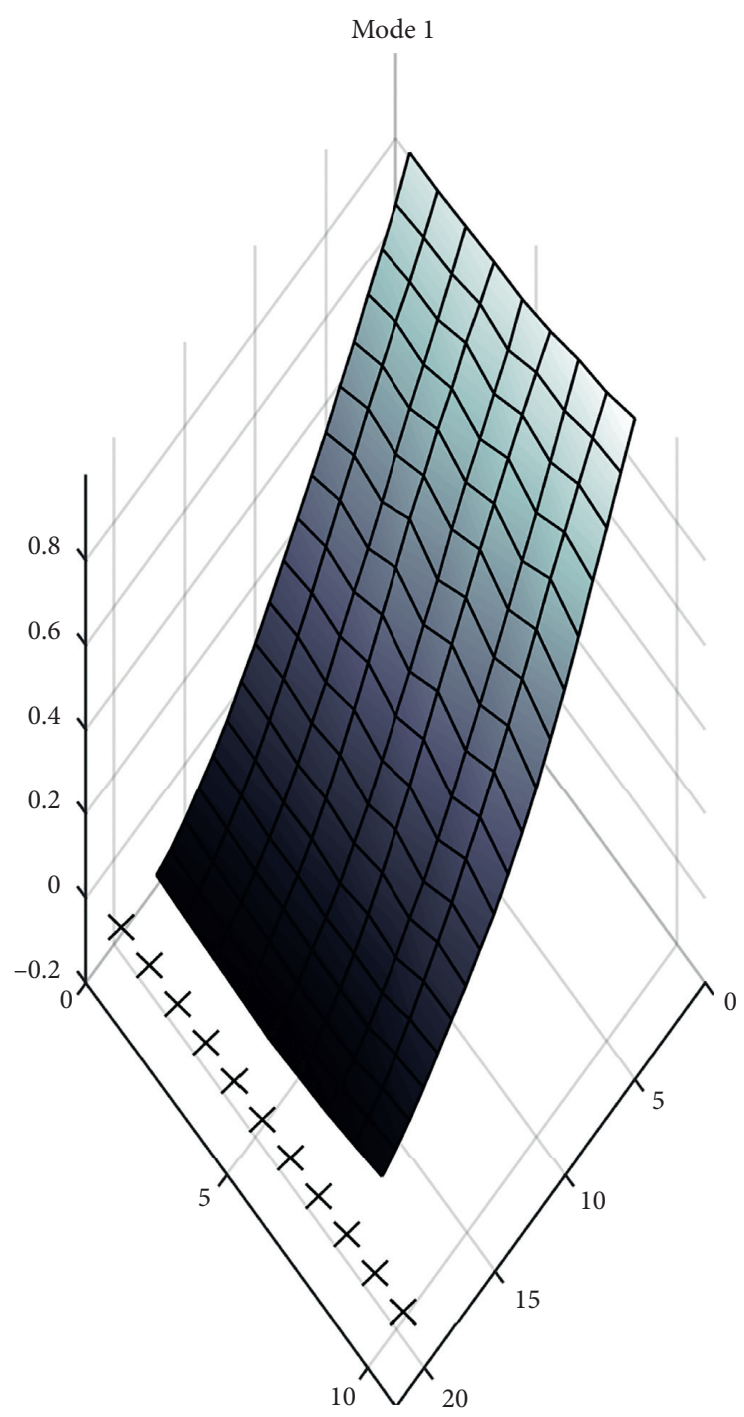

(c)

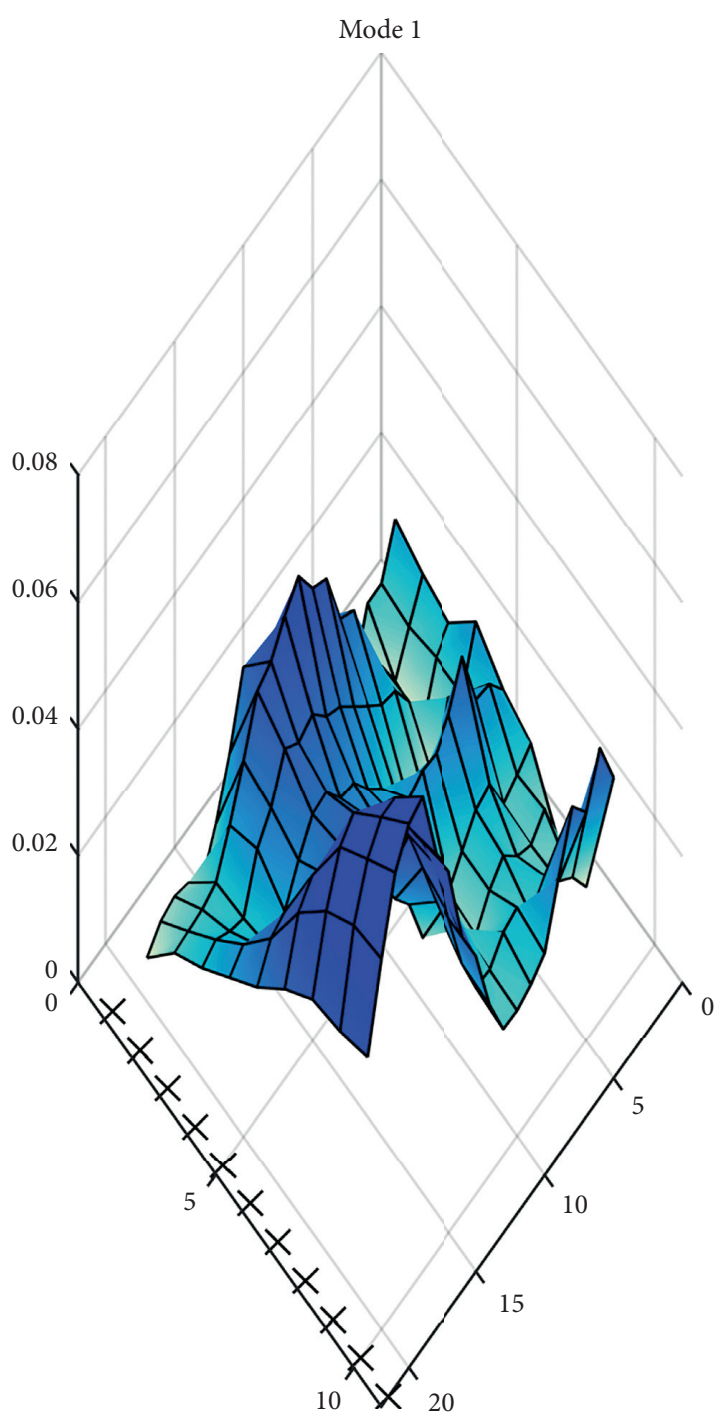

(d)

Figure 12: Continued. 


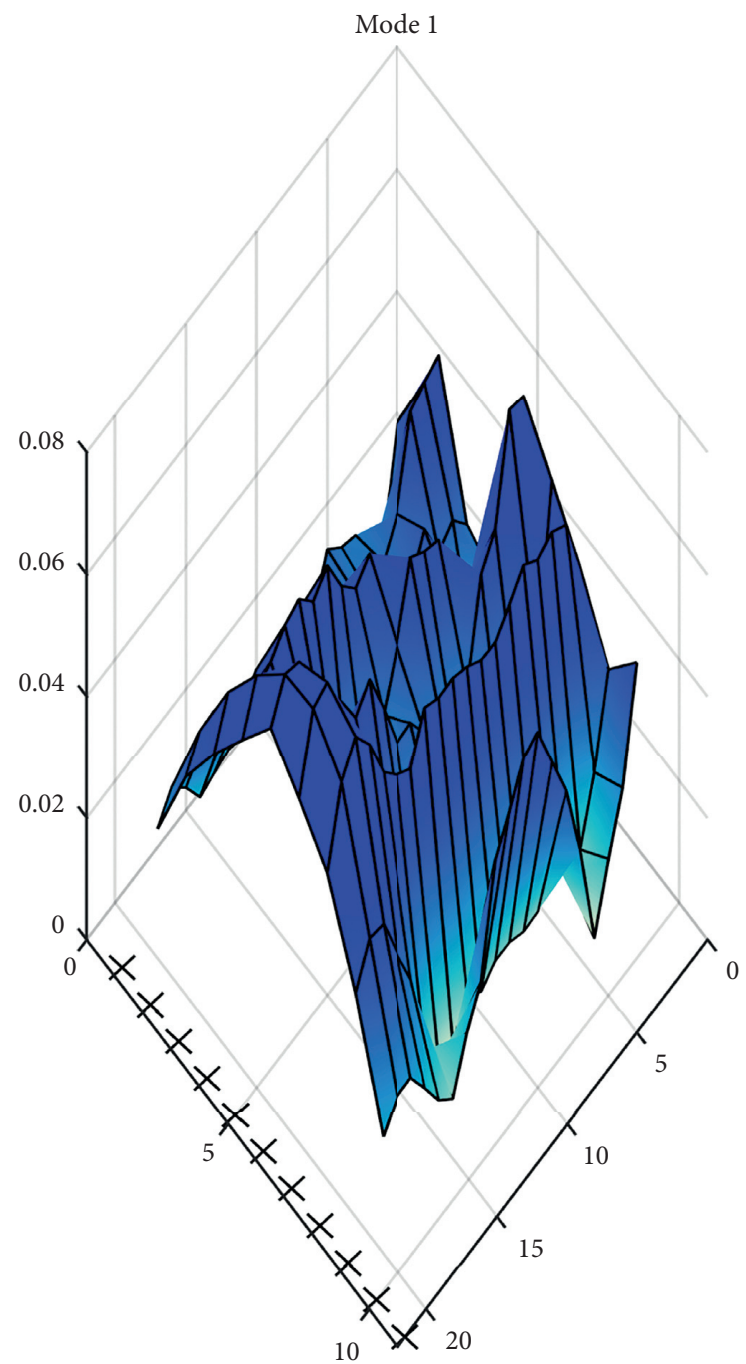

(e)

Figure 12: Comparison of mode shapes acquired for the first mode, for two intact states, (a) before (M\#1) and (b) after reassembly (M\#3), and for (c) damage one fully developed (M\#11) along with differences for the respective mode shapes. (d) M\#1-M\#3 and (e) M\#1-M\#11.

between the consecutive measurements (e.g., cases M\#11 and M\#12 or M\#16 and M\#17). This phenomenon probably decreases the performance of LMF as well: the local filtration is far from perfect, so small local changes tend to be lost in the variability of the intact scenarios.

4.5. Method Indications for Large Damage Case. Large damage case (horizontal cut extending Damage 2 into Damage 3) finally allowed for detection using methods based on MF. Both general MF and LMF allowed for clear detection of damage. The localization of damage is still impossible; that is, the maxima for LMF appear to be located randomly (see Figure 13). The possible explanation can be derived from a straightforward comparison of the recorded mode shapes. In Figure 14, the first three MSs for intact state $\mathrm{M} \# 1$ and fully damaged state $\mathrm{M} \# 26$ are shown next to each other. It can be seen that the local change on which the methods are expected to work is, in fact, present in the mode shapes. The global change induced by damage is, however, much more visible and affects the entire mode shape. Therefore, LMFs are detecting changes alongside the whole plate.

The wavelet-based method did not score any correct results (the indications had values similar to those recorded under intact state). Here, the local change was again not amplified by the subtraction of mode shapes as the whole mode shapes were no longer aligned with each other. Note that MSs are normalized with respect to their maximum value; thus, the actual extension of a mode shape after normalization caused an effective shrinking of a left part of a recorded MS.

4.6. Positive Damage Localization Examples. Despite the general lack of good localization capabilities of the methods, some promising results were obtained for laboratory data. For instance, setting $\mathrm{M} \# 8$ as a reference and $\mathrm{M} \# 20$ as a 


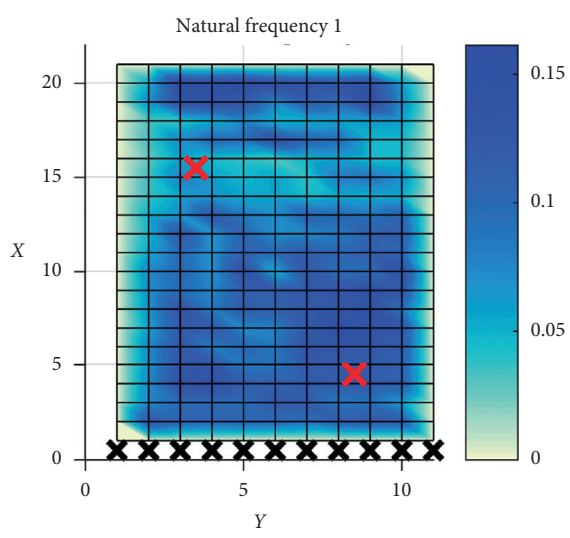

(a)

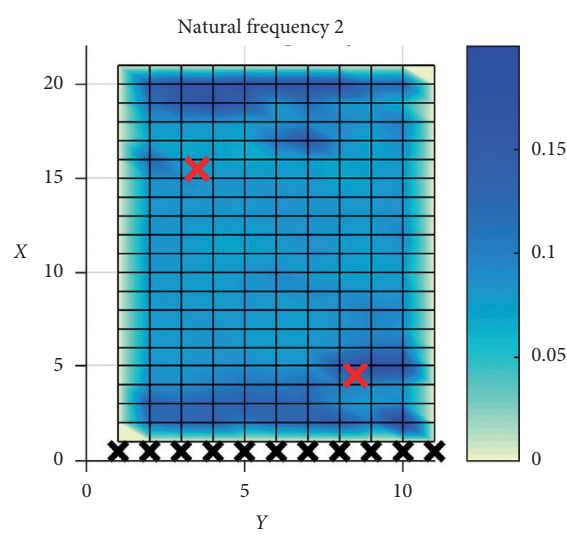

(b)

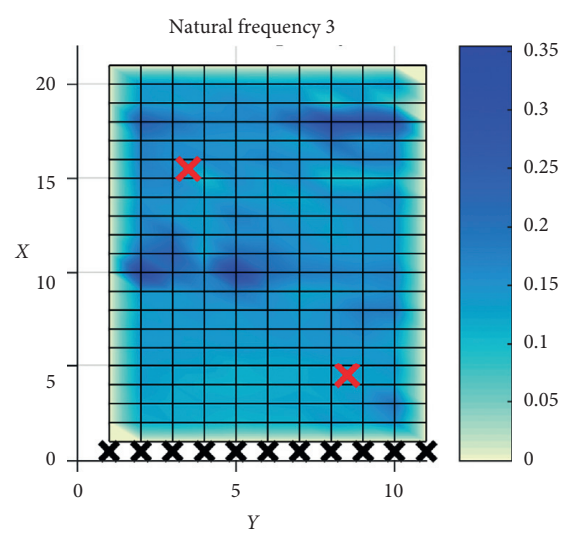

(c)

Figure 13: Outcome of the LMFs tuned to the first three natural frequencies of the plate for maximum damage: (a) natural frequency 1, (b) natural frequency 2 , and (c) natural frequency 3.
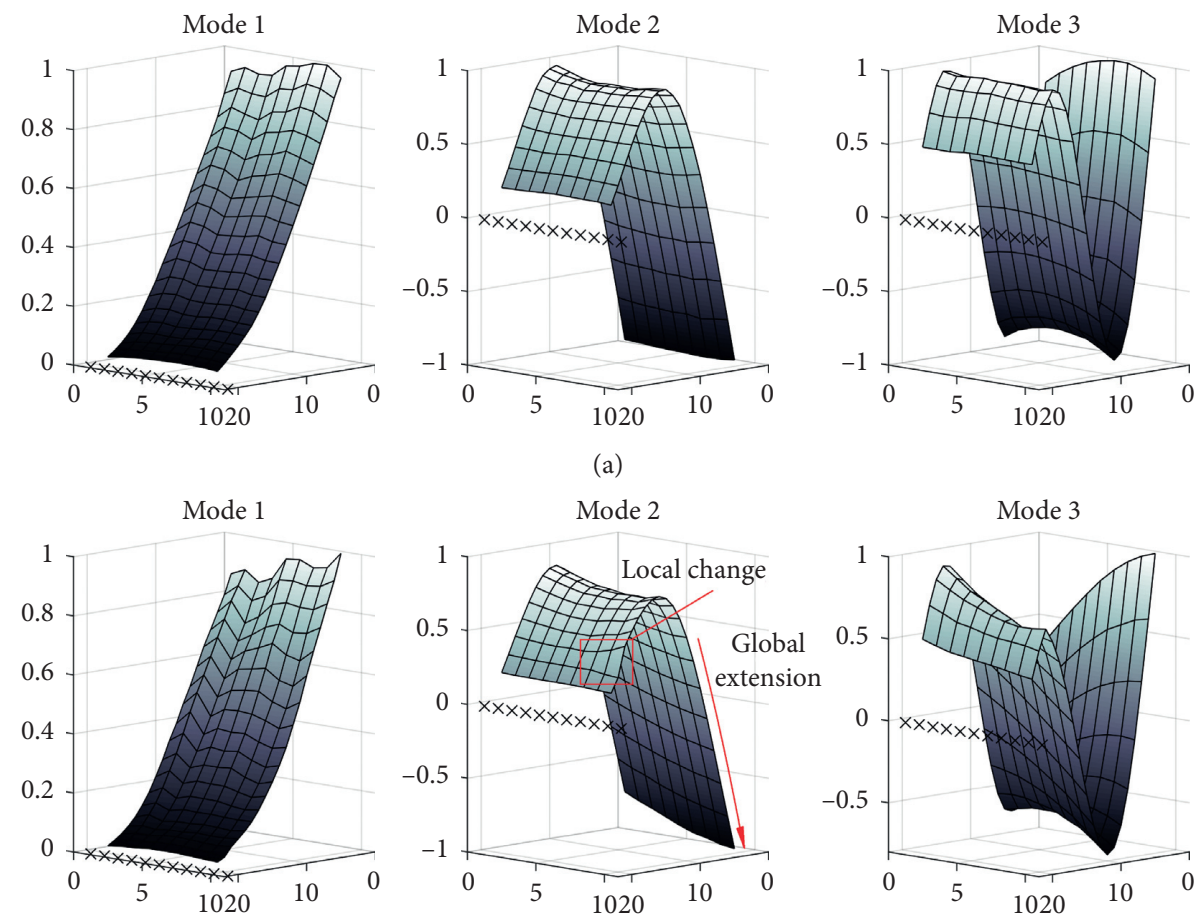

(b)

Figure 14: Comparison of the first three mode shapes for intact state (M\#11) and full damage (M\#26).

measurement to assess and considering third mode shape allowed a WV method to score a result presented in Figure 15(a). Damage 2 appears to be visible, while Damage 1 is not. We could argue that it is because Damage 2 is located closer to the fix, and therefore specimen in that area is subjected to higher strain, rendering mode shape difference to be higher. However, such an inference would not cover the fact that, in many other cases, there are higher indications elsewhere, which suggests that the result should be attributed to pure chance.

Regarding the LMF method, choosing neighborhood size as $2 \times 3$ resulted in diagnosis between $\mathrm{M} \# 1$ and $\mathrm{M} \# 20$ for 2nd LMF presented in Figure 15(b). The choice of this particular neighborhood could be explained by the fact that it is similar to plate shape (we need to have at least 5 points to build 5 LMFs, we want to cover neighborhood points in both $X$ and $Y$ directions, and since the plate has 21 points in $Y$ direction and 11 in $X$ direction, it would be reasonable to choose this neighborhood). Again, however, this explanation does not cover the fact that it is the only neighborhood and the only selection of reference and measurement that allows highlighting areas close to damage in the resulting map. In other words, it is possible to find such a configuration of reference data and configuration of method that 


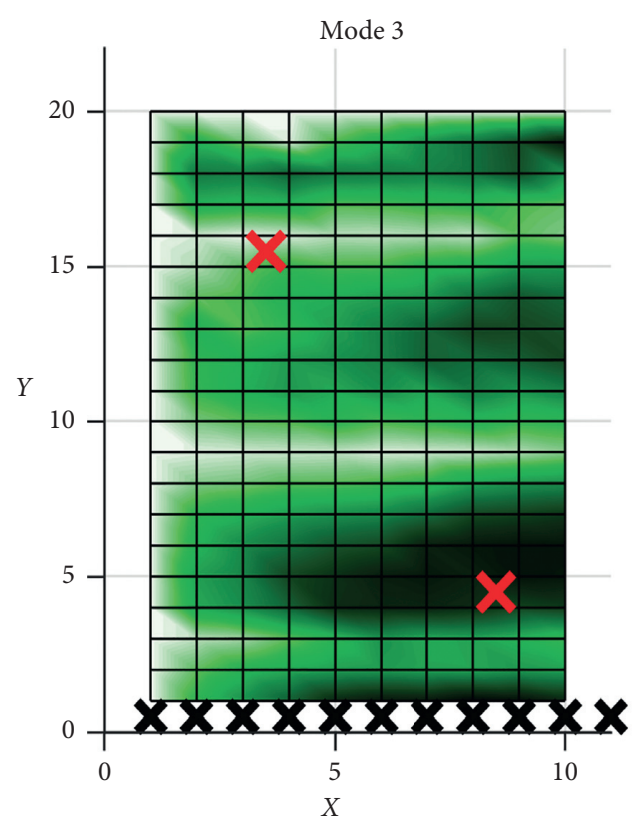

(a)

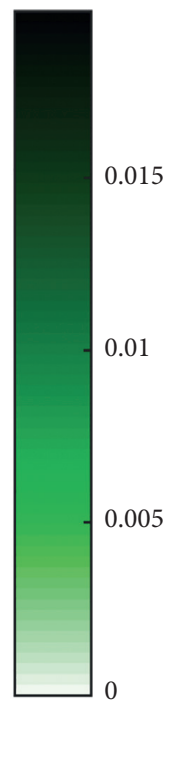

0.015

$0.01 X$

005

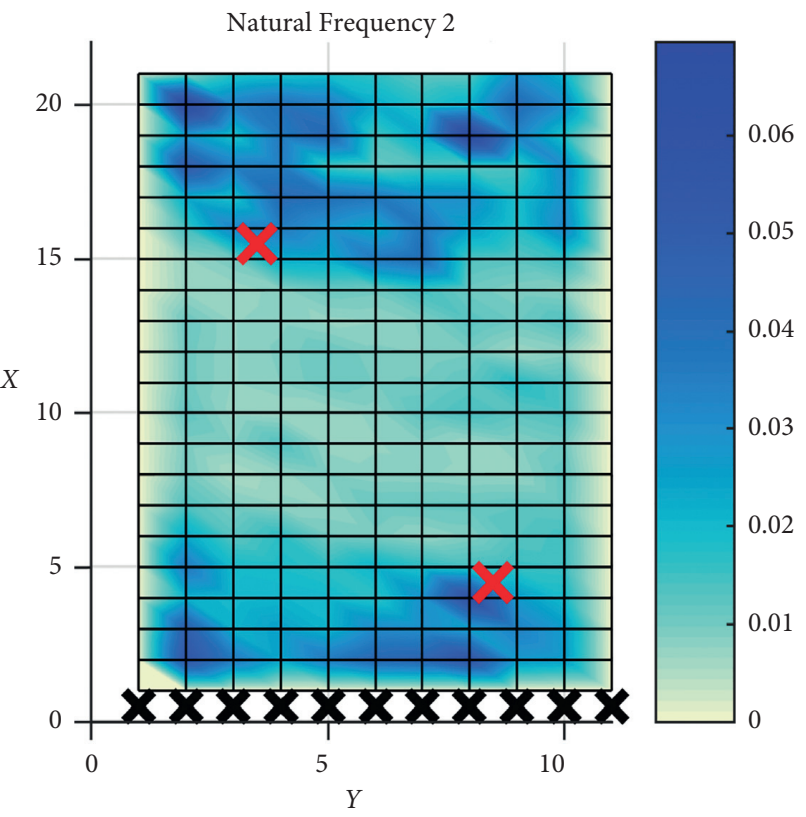

(b)

FIGURE 15: An example of positive localization results obtained using (a) the WV method and (b) the LMF method.

allows showing that the method performs reasonably well. These results, however, are not consistent: application of the similar sets of parameters for other damage cases, other modes, or slight modification of parameter values usually renders the methods to be inefficient again.

4.7. Discussion of the Obtained Localization Results. The motivation for this paper started as an idea to employ two well-known methods of damage detection and localization based on modal analysis, compare them, and perform estimation of the probability of detection for a plate using a well-proven methodology. A working hypothesis was prepared that since the methods score well for 1D scenarios and some work indicating their usage for $2 \mathrm{D}$ structures can also be found, application of the methods for $2 \mathrm{D}$ structures should not prove challenging. However, despite the promising outcome of some preliminary works and clear support of the hypothesis by simulation, it was found that the hypothesis was wrong. The localization of damage using modal-analysis-based tools was not possible under the investigated conditions. The detection of damage was possible only for the MF and LMF methods. The wavelet-based approach was not able to detect the damage. The presented negative results are not caused by the quality of obtained data, as there are works in which similar experiments are successfully performed using, for example, rowing hammer methodology that tends to provide mode shapes of lower quality than those obtained using laser vibrometers [35].

It is worth noting that the conditions of the experiment were much better than those that might be encountered in the field, had the method been applied in practice. The acquired MSs were of high smoothness and quality. The authors tested many methods (usage of $2 \mathrm{D}$ and $1 \mathrm{D}$ wavelets, usage of a difference of mode shapes as a source for the wavelets or the MS themselves, usage of various scales or mother wavelets or spatial interpolation of mode shapes as in [35], usage of different neighborhoods for LMFs, or performing the diagnosis in rows or columns separately). None of these tries rendered any improvement of the obtained result; however, in some, a few promising results were found. Picking a particular mode, a particular set of parameters for a given method, and a particular measurement allowed for registration of a seemingly good result (the highest local indications were found in the proximity of the actual damage). However, since in the vast majority of other (often similar) configurations, the results were entirely different, the few "good" examples were classified as outliers obtained by pure chance.

Unfortunately, due to article size constraints, it is impossible to provide a full account of performed attempts. Nevertheless, the full data used to prepare this paper is available on demand from the corresponding author. It is the authors' opinion that damage of this size (holes of diameters up to $10 \%$ of the width of the specimen) cannot be localized under real-life conditions using the proposed methodology.

There are several explanations to why the methods worked in some setups that are reported in the literature but failed to work in this experiment:

(1) The methodologies reported in the literature did not consider changes in the temperature or reassembly of the test stand. If the experiments were performed without reassembly or temperature-induced changes, the method might arguably work as intended: the threshold for detection would probably be much lower, and small holes in the specimen might have been detected. Still, this observation 
renders the methods not to be usable in practice. Under real-life conditions, it would not be reasonable to assume that the only changes in the structure might be caused by damage (and not its loading, temperature gradients, or reattachment of sensors).

(2) The usage of a laser vibrometer causes the measurement grid to move in relation to the actual plate. When the plate vibrates, the measured point changes slightly. While it should not affect the results to such an extent, it could be the source of the noise. Sensors attached to the plate would limit this possibility, but sensor-based methodologies do not allow for a dense measurement grid again limiting modal-based solutions to damage detection only. Other dense-field measurements include vision-based [36] and rowing hammer-based methodologies [35]. The former are challenging in the acquisition of high modes of vibration and have a trade-off between spatial resolution of measurement of one point and span of measured structure; the latter induce much bigger excitation point errors than measurement point errors obtained using a laser vibrometer.

(3) The methodology fails at cantilever-like support of the plate because of the large amplitude of vibration at the free end of the plate, which causes problems with normalization of the mode shapes. The modes are normalized to their maximum values; thus, any local differences are lost, rendering the wavelet to be useless. Note, for instance, that in works by, for example, Katunin et al. [20] and Abdulkareem et al. [21], the plate is fixed at least at two sides. What is more, in the latter article, the influence of a number of fixed sides was actually tested with the result that four sides fixed render much more explicit damage indications when compared to results obtained for two fixed plate sides. This, however, does not explain good results reported in some other works for plates supported similarly, as in this paper.

(4) The methodology allows for a wide range of possible decisions, thus allowing for picking of results that fit the desired outcome. One could select various modes of vibration, pick different mother wavelets, or tune LMFs to different frequencies, arguing that the damage cannot be localized in particular modes only due to the fact that it is located, for example, in mode's node. This analysis is possible only a posteriori when we already know where the damage is located. From a typical user's point of view, there is no way of establishing which indications should be attributed to actual damage and which to constraints, a curvature of mode shapes, and so on. Under some conditions (e.g., the relative position of damage in mode curvature or type of damage versus used mother wavelet), the method might have worked as intended. However, it does not provide a general solution working under any typical circumstances. In other words, good results can be obtained only under a particular setup, with the geometry of the specimen and damage locations following strict requirements.

(5) It is often generalized that mode shapes are only locally affected by the small damage, but this effect is much more visible for higher modes. This is consistent, for example, with work reported by Blachowski et al. [37] in which a similar phenomenon was not only experimentally observed but also analytically explained (although that structure was not plate-like, the observations and conclusions appeared to be similar to ones discussed in this work).

\section{Summary and Conclusions}

The conclusions of the paper are mixed. On one hand, based on simulation, it was confirmed that the LMF-based method is expected to be applicable not only for beam-like structures (as proven in the literature) but also for plates and provides good damage detection and localization capabilities. It was also found that the method is comparable to the waveletbased method, and since both methods are based on different principles, they could be combined, for example, in a decision fusion system. On the other hand, these results were not confirmed in a practical experiment despite the high quality of input data. The only phenomenon that was confirmed in a laboratory experiment was damage detection by the LMF and MF, but only for very significant damage that could very well be classified as "catastrophic."

Lack of indication from WV method and lack of proper localization from LMF and MF methods do not come from low signal-to-noise ratio as the overall quality of mode shapes is relatively good, there are no outliers, and the obtained difference surfaces are smooth. Although the damage of this size is often reported in the literature as being easy to locate, the outcome of this experiment suggests otherwise. The authors claim that it is not possible to clearly localize damage in plate-like structures using modal-based approaches. If the damage is so large that it changes the mode shapes enough to be detected under practical experimental conditions, it is also too large to cause this effect only locally.

The data used for this experiment, the Matlab codes used to process them, and extract damage indices are available on demand from the corresponding author. We encourage other researchers to copy our experiment and compare the obtained results or use our data to test other modal-based damage localization approaches.

\section{Data Availability}

The data used for the preparation of the paper are available on demand from the corresponding author (Ziemowit Dworakowski,zdw@agh.edu.pl).

\section{Conflicts of Interest}

The authors declare that they have no conflicts of interest. 


\section{References}

[1] P. Gudmundson, "Eigen frequency changes of structures due to cracks, notches or other geometrical changes," Journal of the Mechanics and Physics of Solids, vol. 30, no. 5, pp. 339-353, 1982.

[2] G. C. Pardoen, "Effect of delamination on the natural frequencies of composite laminates," Journal of Composite Materials, vol. 23, no. 12, pp. 1200-1215, 1989.

[3] P. Cawley and R. D. Adams, "The location of defects in structures from measurements of natural frequencies," The Journal of Strain Analysis for Engineering Design, vol. 14, no. 2, pp. 49-57, 1979.

[4] G. Kawiecki, "Modal damping measurement for damage detection," Smart Materials and Structures, vol. 10, no. 3, p. 466, 2001.

[5] R. O. Curadelli, J. D. Riera, D. Ambrosini, and M. G. Amani, "Damage detection by means of structural damping identification," Engineering Structures, vol. 30, no. 12, pp. 3497-3504, 2008.

[6] C. Kyriazoglou, B. H. Le Page, and F. J. Guild, "Vibration damping for crack detection in composite laminates," Composites Part A: Applied Science and Manufacturing, vol. 35, no. 7-8, pp. 945-953, 2004.

[7] M. M. Abdel Wahab and G. De Roeck, "Damage detection in bridges using modal curvatures: application to a real damage scenario," Journal of Sound and Vibration, vol. 226, no. 2, pp. 217-235, 1999.

[8] H. Ahmadian, J. E. Mottershead, and M. I. Friswell, "Damage location indicators from substructure mode shapes," Inverse Problems in Engineering, vol. 8, no. 4, pp. 309-323, 2000.

[9] C. J. Carrasco, R. A. Osegueda, C. M. Ferregut, and M. Grygier, "Damage localization in a space truss model using modal strain energy," in Proceedings of the 15th International Modal Analysis Conference (IMAC), pp. 1786-1792, Orlando, FL, USA, February 1997.

[10] Y. F. Xu, "A photogrammetry-based experimental modal analysis method by tracking visible laser spots," Measurement: Journal of the International Measurement Confederation, vol. 151, pp. 1-13, 2020.

[11] A. C. Altunişik, O. e. Karahasan, A. F. Genç et al., "Modal parameter identification of RC frame under undamaged, damaged, repaired and strengthened conditions," Measurement: Journal of the International Measurement Confederation, vol. 124, pp. 260-276, 2018.

[12] Y. F. Xu, W. D. Zhu, J. Liu, and Y. M. Shao, "Identification of embedded horizontal cracks in beams using measured mode shapes," Journal of Sound and Vibration, vol. 333, no. 23, pp. 6273-6294, 2014.

[13] Y. Xu and W. Zhu, "Non-model-based damage identification of plates using measured mode shapes," Structural Health Monitoring, 2017.

[14] N. Stubbs, J. T. Kim, and C. R. Farrar, "Field verification of a non destructive damage localization and sensitivity estimator algorithm," in Proceedings of the 13th International Modal Analysis Conference, Nashville, TN, USA, 1995.

[15] P. Cornwell, S. W. Doebling, and C. R. Farrar, "Application of the strain energy damage detection method to plate-like structures," Journal of Sound and Vibration, vol. 224, no. 2, pp. 359-374, 1999.

[16] M. P. Limongelli, "The modal surface interpolation method for damage localization," Journal of Physics: Conference Series, vol. 842, no. 1, Article ID 012004, 2017.
[17] M. P. Limongelli, "The surface interpolation method for damage localization in plates," Mechanical Systems and Signal Processing, vol. 118, pp. 171-194, 2019.

[18] A. C. Okafor and A. Dutta, "Structural damage detection in beams by wavelet transforms," Smart Materials and Structures, vol. 9, no. 6, pp. 906-917, 2000.

[19] M. Rucka and K. Wilde, "Application of continuous wavelet transform in vibration based damage detection method for beams and plates," Journal of Sound and Vibration, vol. 297, no. 3-5, pp. 536-550, 2006.

[20] A. Katunin, "Damage identification in composite plates using two-dimensional B-spline wavelets," Mechanical Systems and Signal Processing, vol. 25, no. 8, pp. 3153-3167, 2011.

[21] M. Abdulkareem, N. Bakhary, M. Vafaei, N. M. Noor, and R. N. Mohamed, "Application of two-dimensional wavelet transform to detect damage in steel plate structures," Measurement, vol. 146, pp. 912-923, 2019.

[22] N. G. Pnevmatikos, B. Blachowski, G. D. Hatzigeorgiou, and A. Swiercz, "Wavelet analysis based damage localization in steel frames with bolted connections," Smart Structures and Systems, vol. 18, no. 6, pp. 1189-1202, 2016.

[23] K. Mendrok and T. Uhl, "Experimental verification of the damage localization procedure based on modal filtering," Structural Health Monitoring, vol. 10, no. 2, pp. 157-171, 2011.

[24] K. Mendrok, M. Bochenska, and Z. Dworakowski, "Effectiveness evaluation of the damage localization with a local spatial filtration under variable external conditions," Diagnostyka, vol. 20, no. 1, pp. 55-61, 2018.

[25] Q. Zhang, R. J. Allemang, and D. L. Brown, "Modal filter: concept and applications," in Proceedings of the 8th International Modal Analysis Conference, pp. 487-496, Orlando, FL, USA, 1990.

[26] L. Meirovitch and H. Baruh, "Control of self-adjoint distributed-parameter systems," Journal of Guidance, Control, and Dynamics, vol. 5, no. 1, p. 60, 1982.

[27] A. Deraemaeker and A. Preumont, "Vibration based damage detection using large array sensors and spatial filters," Mechanical Systems and Signal Processing, vol. 20, no. 7, pp. 1615-1630, 2006.

[28] K. Mendrok and T. Uhl, "The application of modal filters for damage detection," Smart Structures and Systems, vol. 6, no. 2, 2010.

[29] K. Mendrok and T. Uhl, "Modal filtration for damage detection and localization," in Proceedings of the Fourth European Workshop on Structural Health Monitoring, Krakow, Poland, 2008.

[30] Z. Dworakowski, L. Ambrozinski, and T. Stepinski, "Data fusion for compensation of temperature variations in Lambwave based SHM systems," in Proceedings of the SPIE Smart Structures NDE, San Diego, CA, USA, 2015.

[31] Z. Dworakowski, L. Ambrozinski, and T. Stepinski, "Multistage temperature compensation method for Lamb wave measurements," Journal of Sound and Vibration, vol. 382, pp. 328-339, 2016.

[32] K. Mendrok, M. Bochenska, and Z. Dworakowski, "Effectiveness evaluation of the damage localization with a local spatial filtration under variable external conditions," Diagnostyka, vol. 20, no. 1, pp. 55-61, 2019.

[33] H. Guan and V. M. Karbhari, "Improved damage detection method based on Element Modal Strain Damage Index using sparse measurement," Journal of Sound and Vibration, vol. 309, no. 3-5, pp. 465-494, 2008. 
[34] A. Ziaja and K. Mendrok, "Mode shapes subtraction and wavelet analysis for damage detection," Diagnostyka, vol. 58, pp. 31-38, 2011.

[35] W. Fan and P. Qiao, "International Journal of Solids and Structures A 2-D continuous wavelet transform of mode shape data for damage detection of plate structures," International Journal of Solids and Structures, vol. 46, no. 25-26, pp. 4379-4395, 2009.

[36] P. Poozesh, A. Sarrafi, Z. Mao, and C. Niezrecki, "Modal parameter estimation from optically-measured data using a hybrid output-only system identification method," Measurement, vol. 110, pp. 134-145, 2017.

[37] B. Blachowski, A. Swiercz, P. Gutkiewicz, J. Szelążek, and W. Gutkowski, "Structural damage detectability using modal and ultrasonic approaches," Measurement, vol. 85, pp. 210$221,2016$. 